Article

\title{
Organic Contaminant Content and Physico-Chemical Characteristics of Waste Materials Recycled in Agriculture
}

\author{
Hannah Rigby ${ }^{1, *}$, Alan Dowding ${ }^{2}$, Alwyn Fernandes ${ }^{3}$, David Humphries ${ }^{4}$, \\ Rupert G. Petch ${ }^{3}$, Christopher K. Reynolds ${ }^{4}$, Martin Rose ${ }^{3}$ and Stephen R. Smith ${ }^{1}$
}

1 Imperial College Consultants Ltd., 58 Prince's Gate, Exhibition Road, London SW7 2PG, UK; E-Mail: s.r.smith@imperial.ac.uk

2 Chemical Contaminants and Residues Branch, Food Safety Policy, Food Standards Agency, Aviation House, 125 Kingsway, London, WC2B 6NH, UK;

E-Mail: alan.dowding@foodstandards.gsi.gov.uk

3 Fera Science Ltd., Sand Hutton, York, YO41 1LZ, UK;

E-Mails: alwyn.fernandes@fera.co.uk (A.F.); steve.petch@fera.co.uk (R.G.P.); martin.rose@fera.co.uk (M.R.)

4 Centre for Dairy Research, Food Production and Quality Division, School of Agriculture, Policy and Development, The University of Reading, P.O. Box 237, Reading, Berkshire, RG6 6AR, UK; E-Mails: d.j.humphries@reading.ac.uk (D.H.); c.k.reynolds@reading.ac.uk (C.K.R.)

* Author to whom correspondence should be addressed; E-Mail: hannah.rigby04@imperial.ac.uk; Tel.: +44-207-594-6018.

Academic Editor: Les Copeland

Received: 2 September 2015 / Accepted: 18 November 2015 / Published: 17 December 2015

\begin{abstract}
A range of wastes representative of materials currently applied, or with future potential to be applied, to agricultural land in the UK as fertilisers and soil improvers or used as animal bedding in livestock production, were investigated. In addition to full physico-chemical characterization, the materials were analysed for a suite of priority organic contaminants. In general, contaminants were present at relatively low concentrations. For example, for biosolids and compost-like-output (CLO), concentrations of polychlorinated dibenzo- $p$-dioxins/dibenzofurans (PCDD/Fs) and polychlorinated biphenyls (PCBs) were approximately 1-10 and 5-50 times lower, respectively, than various proposed or implemented European limit values for these contaminants in biosolids or composts applied to agricultural land. However, the technical basis for these limits may require re-evaluation in some cases. Polybrominated, and mixed halogenated, dibenzo- $p$-dioxins/dibenzofurans
\end{abstract}


are not currently considered in risk assessments of dioxins and dioxin-like chemicals, but were detected at relatively high concentrations compared with PCDD/Fs in the biosolids and CLOs and their potential contribution to the overall toxic equivalency is assessed. Other 'emerging' contaminants, such as organophosphate flame retardants, were detected in several of the waste materials, and their potential significance is discussed. The study is part of a wider research programme that will provide evidence that is expected to improve confidence in the use of waste-derived materials in agriculture and to establish guidelines to protect the food chain where necessary.

Keywords: ash; agriculture; biosolids; compost-like-output; food; organic contaminants; recycling; waste

\section{Introduction}

Recycling of waste materials is encouraged across Europe to reduce waste sent to landfill or incineration [1]. Increasingly, recycled materials are used in food production for purposes such as animal bedding or as soil improvers and fertilisers. Biosolids have been applied extensively to agricultural land for decades and the impacts on human health are well researched [2], but emerging contaminants need to be considered. Certain outputs from waste combustion processes (e.g., meat and bonemeal ash (MBMA), poultry litter ash (PLA) and paper sludge ash (PSA)) also demonstrate agronomic benefit as soil amendments and other materials provide alternative types of animal bedding (e.g., untreated recycled waste wood (RWW), dried paper sludge (DPS), PSA), and are beneficially used in agriculture as alternatives to landfill disposal. The management of municipal, and commercial and industrial solid wastes by mechanical biological treatment (MBT) is also expanding as a means of waste valorisation and landfill diversion and the stabilised biodegradable output from such processes, described as compost-like-output (CLO), has value as a soil conditioning agent [3]. Whilst land application of CLO is currently not permitted in the UK, it is widely practiced in other countries in Europe and in Australia, and pressure could increase to permit application of high quality biocompost to land in the UK. Ash residuals from combustion processes and CLO can also potentially contain contaminants that could represent a hazard to the human food chain $[4,5]$.

A UK Food Standards Agency (FSA) funded research programme is underway, with the overall aim of investigating the potential transfer of organic contaminants into food arising from the use of recycled waste in agriculture [6]. The research will provide a quantitative assessment of the potential transfer coefficients of principal and emerging organic contaminants to dairy livestock and milk from: (i) recycled wastes used as bedding in dairy production (RWW, PSA, DPS); (ii) biosolids and CLO incorporated into the soil and from direct feed contamination with biosolids; and (iii) PLA, MBMA and PSA incorporated into the soil. Additionally, the research will investigate the potential transfer of selected organic contaminants to crops by: (i) screening contaminant transfers using a plant uptake bioassay under controlled environmental conditions; (ii) assessing uptake by a high lipid containing root crop, also under controlled conditions and representing a worst-case exposure route for the food-chain from land applied organic contaminants; and (iii) conducting a field trial to investigate transfers to cereal grain. 
A range of priority established and emerging organic compounds, which would pose a potential risk to human health if they transferred to food products in significant quantities, are under investigation. Polycyclic aromatic hydrocarbons (PAHs), and polychlorinated dibenzo- $p$-dioxins/dibenzofurans (PCDDs/Fs), which can arise through incomplete combustion, and polychlorinated biphenyls (PCBs), which were widely used in products such as dielectric fluid and paint until the 1970s, are persistent environmental pollutants that can also occur in waste wood [7]. Polybrominated dibenzo- $p$ dioxins/dibenzofurans (PBDD/Fs), polybrominated biphenyls (PBBs), mixed halogenated dibenzo- $p$ dioxins/dibenzofurans (PXDD/Fs) and mixed halogenated biphenyls (PXBs) are related compounds to PCDDs/Fs and PCBs, but little is currently known about their presence in the environment and risk to human health. Perfluoroalkyl compounds (PFASs) are used in, or derived from, nonstick cookware, stain-resistant textiles, coatings on food packaging, components of fire-fighting foam and in many industrial applications including metal plating, hydraulic fluids and surfactants. These compounds are of interest as they have a degree of water solubility [8] and they can therefore be taken up by crops e.g., [9,10]. Polychlorinated napthalenes (PCNs) have dioxin-like properties, and are used in applications such as dielectric fluids, engine oil additives and lubricants [5].

Plasticisers (phthalates, including di(2-ethylhexyl)phthalate (DEHP)), chlorinated paraffins (CPs) (plasticizers, flame-retardants, lubricants and paint additives), chlorobenzenes (CBs) (previously used in pesticides and personal care products) and polycyclic musks (PCMs) (personal care products) were amongst the other persistent organic pollutants investigated.

The programme is unique in the range of waste materials and organic contaminants under investigation and will provide vital information necessary to inform the development of a methodology and quality standards to assess the suitability of new waste materials for recycling in agriculture.

This paper presents the findings of the initial stages of the research programme. The specific objectives addressed in the paper are: (i) identify and describe at least two representative examples of each recycled waste type used in agriculture as fertilisers and soil amendments or as bedding for livestock production; (ii) assess the chemical properties of the waste materials including a range of priority organic contaminant compounds that may present a potential risk to the human food chain; and (iii) examine the chemical properties of the wastes in comparison to the scientific literature, available standards for waste materials and the concentrations of the compounds found in environmental samples.

\section{Materials and Methods}

\subsection{Selection, Collection and Sampling of Waste Materials}

The materials under investigation were biosolids (treated sewage sludge), MBMA and PLA, representating a range of recycled waste materials currently applied to agricultural land in the UK as sources of plant nutrients, and PSA, which is used as an agricultural liming agent. Additionally, CLO from the MBT of municipal solid waste (MSW) was included as it has future potential as a source of nutrients in agriculture. A range of recycled materials used as livestock bedding were also selected, including RWW, DPS from paper manufacturing and PSA, which is used as a desiccant in livestock bedding. A high degree of variability in the chemical composition of the materials was anticipated; hence, at least two examples within each waste category were collected where possible. This strategy was designed to increase the 
probability of finding representative materials containing the compounds of interest so that the potential for transfer to the food chain could be examined. Details of the wastes selected for the programme are provided in Table 1. The materials listed were collected or delivered by the producer and stored in a cool, dry agricultural storage shed in suitable containers or packaging.

Representative composite sub-samples of each waste were collected for analysis. The biosolids were collected from two of the largest wastewater treatment plant in the UK serving major urban populations with combined sewage flows from domestic and industrial inputs, and representing potentially worst-case examples of contemporary biosolids chemical contamination. The selected CLOs were two of the more highly refined materials currently produced by MBT of MSW in the UK and, whilst not currently used in agriculture, they represented materials with the greatest potential for future use on arable land. The biosolids and CLO were sub-sampled at collection at the production site, and the remaining materials were sampled shortly after delivery. Sub-samples of approximately $3 \mathrm{~kg}$ fresh weight (FW) of each of the waste materials were collected and delivered to the analytical laboratory at the Food and Environment Research Agency (Fera, York, UK) in cool boxes with ice-packs by overnight courier. The sub-samples (except for the wood wastes) were collected in $1 \mathrm{~L}$ food-grade polypropylene containers lined with dichloromethane (DCM)-swabbed aluminium foil. The wood wastes were collected in $5 \mathrm{~L}$ polypropylene containers, also lined with DCM-swabbed foil. Additional sub-samples of biosolids and CLO were provided for DEHP analysis; approximately $1 \mathrm{~kg}$ of each material was collected in glass Duran bottles, which had been prepared by heating in a muffle furnace at $400{ }^{\circ} \mathrm{C}$ for $4 \mathrm{~h}$. Dichloromethane-swabbed foil was placed between the bottle and the lid.

On receipt at Fera, biowastes (biosolids and CLO) were frozen prior to analysis, whereas dry wastes (RWWs, ash, DPS) were stored as received. Samples were mixed thoroughly before sub-sampling prior to preparation and extraction for organic contaminant analysis.

An additional set of sub-samples of approximately $500 \mathrm{~g}$ of each waste was collected in $1 \mathrm{~L}$ polypropylene containers and delivered to a NAMAS accredited laboratory (NRM Laboratories, Bracknell, England) for analysis of routine physico-chemical properties.

\subsection{Organic Contaminant Analysis}

2.2.1. Polychlorinated Dibenzo- $p$-dioxins/Dibenzofurans (PCDD/Fs), Polychlorinated Biphenyls (PCBs), Polybrominated Dibenzo- $p$-dioxins/Dibenzofurans (PBDD/Fs), Polybrominated Biphenyls (PBBs) and Polybrominated Diphenyl Ethers (PBDEs)

The method used for the preparation, extraction and analysis of samples $[11,12]$ forms part of the CEN method-EN16215:2012 for PCDD/F and PCB analysis. In brief, samples were fortified with ${ }^{13} \mathrm{C}$-labelled analogues of target compounds and exhaustively extracted using mixed organic solvents. PBDEs and ortho substituted $\mathrm{PCBs} / \mathrm{PBBs}$ were separated from non-ortho substituted $\mathrm{PCBs} / \mathrm{PBBs}$, $\mathrm{PCDD} / \mathrm{Fs}$ and PBDD/Fs by fractionation on activated carbon. The two fractions were further purified using adsorption chromatography on alumina. Analytical measurement was carried out using high resolution gas chromatography-high resolution mass spectrometry (HRGC-HRMS) for all analytes apart from the ortho-substituted PCBs which were analyzed by high resolution gas chromatography-low resolution mass spectrometry (HRGC-LRMS). 
Table 1. Description of wastes used in agriculture or with potential to be used in agriculture collected for the research program.

\begin{tabular}{|c|c|c|}
\hline Type & Sample ID & Waste Description \\
\hline Biosolids & Biosolids1 & $\begin{array}{l}\text { Pre-pasteurised, dewatered, mesophilic anaerobically digested wastewater treatment sludge, } 6 \text { weeks on cake storage pad. } \\
\text { Collected from a large treatment works, serving a population of } 2.1 \text { million (M) accepting combined domestic and } \\
\text { industrial wastewater. } \\
\text { Dewatered, mesophilic anaerobically digested wastewater treatment sludge. Conventional treatment status-anaerobic } \\
\text { digestion process: } 36^{\circ} \mathrm{C}-38^{\circ} \mathrm{C} \text {, Hydraulic Retention Time (HRT) } 15-18 \text { days, followed by } 9 \text { days HRT in secondary liquid } \\
\text { digestion tanks; } 14 \text { days on cake pad. Collected from large treatment works, serving a population of } 1.75 \mathrm{M} \text { accepting } \\
\text { combined domestic and industrial wastewater. }\end{array}$ \\
\hline $\begin{array}{l}\text { Compost like output (CLO) } \\
\text { from MBT }\end{array}$ & CLO1 & $\begin{array}{l}\text { The mechanically separated organic fraction of MSW is composted, under forced aeration with daily turning, in two phases, } \\
\text { for } 6 \text { weeks. The final refinement stage removes all materials over } 12 \mathrm{~mm} \text { and heavy particles. CLO is currently used for } \\
\text { land restoration. It is tested weekly for E. coli and Salmonella and is animal by-product compliant. Selected due to high } \\
\text { level of refinement compared to other materials currently produced. } \\
\text { The mechanically separated }<50 \mathrm{~mm} \text { organic fraction (approximately } 42 \% \text { of original MSW) undergoes in-vessel } \\
\text { composting. Oversized material from green waste composting is blended with maturation material (passed through two } \\
\text { barriers and the maturation pad) in a ratio of } 2: 1 \text {. The fresh shredded organic fraction is blended with the } 2: 1 \text { blend at a ratio } \\
\text { of } 4: 1 \text { to improve aeration. The material spends }<14 \text { days in Barrier } 1 \text {, followed by Barrier } 2 \text {, where it is required to reach } \\
\text { a temperature of } 60^{\circ} \mathrm{C} \text {, followed by } 4 \text { weeks on a maturation pad. Selected due to high level of refinement compared to } \\
\text { other materials currently produced. }\end{array}$ \\
\hline $\begin{array}{l}\text { Meat and bone meal ash } \\
\text { (MBMA) }\end{array}$ & MBMA1 & $\begin{array}{l}\text { The MBMA is produced in a fluidised bed incineration plant. The feedstock is a minimum of } 80 \% \text { animal tissue waste, plus } \\
\text { a maximum of } 20 \% \text { sludges from cleaning during the preparation and processing of foods of animal origin, dairy industry } \\
\text { wastes, non-hazardous pharmaceutical waste, edible oils and fats, compost liquor from Quality Protocol (QP) [13] and } \\
\text { Publically Available Specification (PAS) } 100 \text { [14] compliant plants, and detergent washings. Combustion temperatures } \\
\text { are }>850{ }^{\circ} \mathrm{C} \text { in bed, and } \sim 90{ }^{\circ} \mathrm{C}-950{ }^{\circ} \mathrm{C} \text { in freeboard (air above bed). The amount of ash produced is } 10,000-11,000 \text { t/y } \\
\text { (from } \sim 50,000 \mathrm{t} \text { of MBM). Ash is } \sim 80 \% \text { fly ash, } 20 \% \text { bed ash. The MBMA has End-of-Waste approval. } \\
\text { Feedstock for fluidised bed meat and bone meal (MBM) combustion plant is from Defra (Department for food, environment } \\
\text { and rural affairs) compliant renderers. MBMA produced has End-of-Waste approval. }\end{array}$ \\
\hline
\end{tabular}


Table 1. Cont

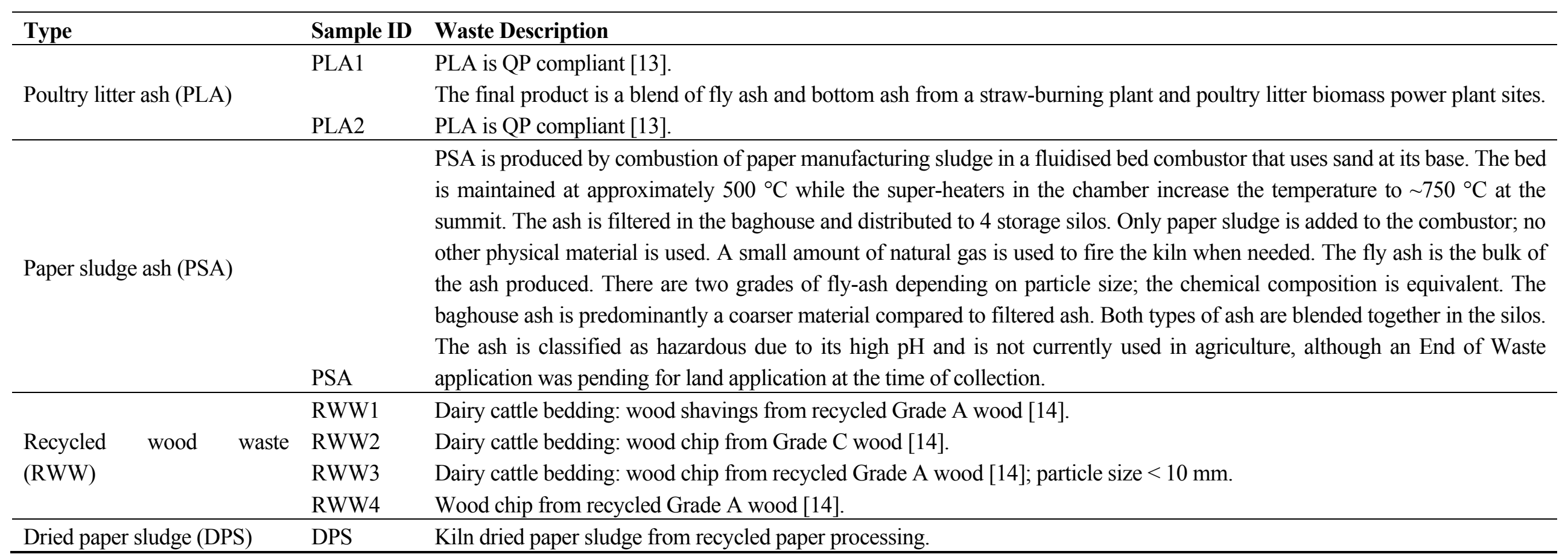


The analytical method is accredited (UKAS) to ISO 17025 standards, with the inclusion of an in-house reference material (RM) and method blanks which were evaluated prior to reporting the sample data and were used to determine the limits of detection. Further quality assurance measures included the successful participation in available international inter-comparison exercises such as Dioxins in Food-2011 to 2014, and European Union Reference Laboratory (EURL) organised Proficiency Test (PT) exercises on dioxins, dioxin-like PCBs, ICES-6 PCBs and PBDEs. Additionally, quality control evaluation for the accompanying data followed the criteria specified for chlorinated dioxins and PCBs [15].

\subsubsection{Mixed Halogenated Dibenzo- $p$-dioxins/Dibenzofurans (PXDD/Fs) and Mixed Halogenated Biphenyls (PXBs)}

The methodology used for the determination of PXDD/Fs and PXBs has been described in detail by Fernandes et al. [16]. In brief, a representative sample aliquot was fortified with nine ${ }^{13} \mathrm{C}$ labelled internal standards (a mix of eight, Br-Cl substituted dioxins, furans and biphenyls, and 2,3,7,8-TCDD), and allowed to equilibrate for at least one hour. The sample was blended and purified on a multilayer acid/base-modified silica column. This was followed by dual activated carbon column fractionation of the mono-ortho substituted PXBs from the di-tetra ortho substituted PXBs (which were discarded), and the non-ortho substituted PXBs and the PXDD/Fs. The extracts resulting from both fractions were analysed by HRGC-HRMS at a resolution of 13,500 to 15,000 . The measurements were performed on a Micromass Autospec Ultima high resolution mass spectrometer coupled to a Hewlett Packard 6890N gas chromatograph fitted with a $60 \mathrm{~m} \times 0.25 \mathrm{~mm}$ i.d. J\&W DB-5 MS fused silica capillary column $(0.25 \mu \mathrm{m}$ film thickness) and a programmable temperature vaporisation (PTV) injector (Gerstel, Mülheim an der Ruhr; Germany) operated in constant flow ( $\sim 1 \mathrm{~mL} / \mathrm{min}$ helium) mode.

\subsubsection{Polycyclic Aromatic Hydrocarbons (PAHs)}

The following PAHs were determined: acenaphthene, acenaphthylene, fluorene, phenanthrene, anthracene, fluoranthene, benzo[c]fluorene, pyrene, benzo[e]pyrene, benzo[b]naptho[2,1-d]thiophene, anthanthrene, coronene, benzo[ghi]fluoranthene, benz[a]anthracene, chrysene, benzo[b]fluoranthene, benzo[j]fluoranthene, benzo[k]fluoranthene, benzo[a]pyrene, cyclopenta[c,d]pyrene, indeno[123cd]pyrene, dibenzo[ah]anthracene, benzo[ghi]perylene, dibenzo[al]pyrene, dibenzo[ae]pyrene, dibenzo[ai]pyrene, dibenzo[ah]pyrene and the substituted PAH, 5-methylchrysene.

The PAH analytical methodology [17] was based on internal standardisation $\left({ }^{13} \mathrm{C}\right)$ with gas chromatography mass spectrometry (GC-MS) measurement. An aliquot of the homogenised sample was fortified with ${ }^{13} \mathrm{C}$-labelled analogues of target compounds and saponified with methanolic potassium hydroxide. The extracted PAH solutions were purified in two stages with a dimethylformamide (DMF)/cyclohexane partition followed by adsorption chromatography on activated silica. A sensitivity standard was added to the purified extracts and these were measured using HRGC-LRMS.

Further quality assurance measures included the successful participation in available international inter-comparison exercises such as the Food Analysis Performance Assessment Scheme (FAPAS), and EURL PT exercises on PAHs. 


\subsubsection{Hexabromocyclododecanes (HBCDs), Pentabromocyclododecene (PBCD) and} Tetrabromobisphenol A (TBBPA)

The analysis of HBCDs, PBCD and TBBPA in the waste samples was carried out in duplicate. Sample aliquots, including a procedural blank and a RM, were fortified with ${ }^{13}$ Carbon labelled analogues of TBBPA, $\alpha H B C D, \beta H B C D$, and $\gamma H B C D$ and allowed to stabilise before blending with hexane:dichloromethane, 60:40 (v/v) and hydrolysis of the matrix using acid modified silica. The extract recovered from this process was filtered, washed, concentrated and solvent exchanged to a methanol:water solvent system prior to analysis by high pressure liquid chromatography-tandem mass spectrometry (HPLC-MS/MS) in the multiple reaction monitoring mode (MRM).

The parameters used for evaluating data quality were similar to those used for other analyses. Method limits of detection, evaluated through method blank determinations, were typically $<0.01 \mu \mathrm{g} \mathrm{kg} \mathrm{whole}^{-1}$ weight and analytical recoveries were generally within the range of 50\%-100\%. Aliquots of all the samples analysed were fortified with native analytes and the concentrations of recovered analytes measured were in good agreement with fortification levels. Additionally a fortified in-house RM was also analysed regularly with the samples and returned values that were in good agreement with fortification levels.

\subsubsection{Polychlorinated Napthalenes (PCNs)}

A full description of the reagents, reference standards and procedures used for the extraction and analysis of PCNs has been reported by Fernandes et al. [18]. In brief, samples were fortified with ${ }^{13} \mathrm{C}$-labelled analogues of target compounds and exhaustively extracted using mixed organic solvents. PCNs were chromatographically fractionated from potential interferents, such as PCBs, using activated carbon. The extract was further purified using adsorption chromatography on alumina. Analytical measurement was carried out using HRGC-HRMS. Additional control was provided by the inclusion of method blanks and a RM.

The quality control criteria used for evaluating data are very similar to the accredited methodology used for the chlorinated dioxins and PCBs [18]. There are no available RMs specific to PCNs, but the same material used for PCDD/F and PCB analysis (cod liver oil) was analysed during the course of this work with results showing good consistency and agreement with established values.

\subsubsection{Screen for Perfluoroalkyl Substances (PFASs)}

The sample extraction procedure applied to PFASs is described by Lloyd et al. [19]. Briefly, quadruple 1-10 g portions of each homogenised sample were transferred into Falcon tubes $(50 \mathrm{~mL})$. The appropriate volumes of internal standard (IS) and standard addition mixtures were added, to prepare two unspiked portions, one overspiked at the reporting level $(1 \mu \mathrm{g} \mathrm{kg}-1)$ and one portion at 10-times the reporting level $\left(10 \mu \mathrm{g} \mathrm{kg}^{-1}\right)$. The sample portions were homogenised for 1-3 min as required in $20 \mathrm{~mL}$ of methanol with an Ultra Turrax (IKA-Wenke GmBH, Staufen, Germany) (T25 basic with S25N blade). When homogenised, more methanol was added ( $\sim 40 \mathrm{ml}$ in total) and mixed, while withdrawing the Ultra Turrax blade. Samples were agitated overnight (16h), then centrifuged (15 min, $5000 \mathrm{rpm})$. The supernatant methanol extracts were evaporated under a nitrogen stream $\left(80^{\circ} \mathrm{C}\right.$, in silyanised glass vials $)$ just to dryness, and the residues were re-dissolved in aqueous $\mathrm{KOH}(25 \mathrm{~mL}, 0.01 \mathrm{M}$, sonication $10 \mathrm{~min})$. The aqueous 
extracts were re-centrifuged (15 min, $5000 \mathrm{rpm})$. When required, the supernatants were poured in one continuous gentle movement, without breaking up the floating materials, or disturbing the sediment, into a funnel connected onto the top of a preconditioned solid phase extraction (SPE) cartridge (weak anion exchange). The cartridges were loaded at a constant drip rate by increasing from gravity feed to full vacuum as required. After loading, the cartridges were washed with ammonium acetate $(2 \times 6 \mathrm{~mL}, 25 \mathrm{mM}, \mathrm{pH} 4.5)$ and eluted with basic methanol ( $4 \mathrm{~mL}, 0.1 \%$ ammonia). The eluates were reduced under a stream of nitrogen gas $\left(60^{\circ} \mathrm{C}\right)$, just to dryness and the residues were taken up in methanol $(400 \mu \mathrm{L}$, sonication 10 $\mathrm{min})$. Extracts were transferred into silyanised glass microvials $(300 \mu \mathrm{L})$ for HPLC-MS/MS determination.

The analysis was performed by coupling a 1290 Infinity HTS Injector (Agilent/Analytics, Switzerland) and a 1290 Infinity LC Pump with column oven (Agilent, Germany) to a 6490 Triple Quadrupole Mass

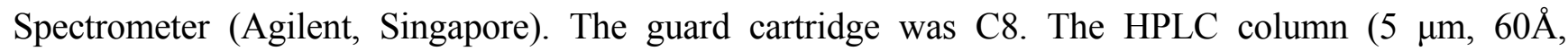
$2.1 \times 150 \mathrm{~mm}$, HiChrom, UK) was Fluorosep RP Octyl phase, thermostatically held at $40{ }^{\circ} \mathrm{C}$ in the column oven. The injection volume was $5 \mu \mathrm{L}$. The gradient programme (methanol: aqueous ammonium formate, $5 \mathrm{mM}, \mathrm{pH}$ 4) was: $10 \%$ methanol increasing to $30 \%$ at $0.1 \mathrm{~min}$ (linear gradient), to $75 \%$ at $7 \mathrm{~min}$ and $100 \%$ methanol at $10 \mathrm{~min}$, this was held for $5 \mathrm{~min}$ (column washing), then decreased to $10 \%$ methanol at $15.1 \mathrm{~min}$ for $4.9 \mathrm{~min}$ (column re-conditioning). MassHunter B.04.0 software was used for instrument control, file acquisition and peak integration. The MS detector in multiple MRM mode with a Jet Stream electrospray source operating in negative polarity was used for quantitative analysis. Data acquisition was conducted in one simultaneous acquisition schedule without separation into chromatographic acquisition windows. Instrumental parameters were optimised by injection of standard solutions directly into the LC flow $\left(1 \mu \mathrm{g} \mathrm{mL}^{-1}\right.$ in $1: 1$ methanol:aqueous ammonium formate $\left.(5 \mathrm{mM}, \mathrm{pH} 4)\right)$. The source conditions were: drying gas temp $110^{\circ} \mathrm{C}$, drying gas flow $18 \mathrm{~L} / \mathrm{min}$, nebulizer 25 psi, sheath gas flow temp $400{ }^{\circ} \mathrm{C}$, sheath gas flow $12 \mathrm{~L} / \mathrm{min}$, capillary voltage $3000 \mathrm{v}$, nozzle voltage $0 \mathrm{v}$. An Excel spreadsheet was used to calculate PFAS concentrations from the standard additions.

\subsubsection{Gas Chromatography-Time of Flight-Mass Spectrometry (GC-ToF-MS) Screen}

Duplicate portions of each sample (between 3 and $10 \mathrm{~g}$ depending upon the physical form of the sample) were transferred to a glass vial. Acetonitrile (Rathburn, Walkerburn, Peeblesshire, UK) (20 mL) was added, and the vials were capped and shaken for 18 hours on an orbital shaker. The vials were centrifuged (2000 rpm for $10 \mathrm{~min}$ ) and the solvent was transferred to a clean glass vial before evaporation at $40{ }^{\circ} \mathrm{C}$. The residue was re-dissolved in acetonitrile $(1 \mathrm{~mL})$, vortex mixed and transferred to a vial for GC-ToF-MS analysis. Standards for a number of target compounds were also prepared including phthalates, CPs, CBs, PCMs and 1,2-bis(2,4,6-tribromophenoxy)ethane (BTBPE).

The standards and extracts were analysed by gas chromatography (GC) with time-of-flight mass spectrometric (ToF-MS) detection using a 7890B GC system and a 7200 Accurate-mass quadrupleToF GC-MS (Agilent, Santa Clara, CA, USA) along with a Gerstel Multiflex Sampler (Anatune, Cambridge, UK). Chromatographic separation was achieved on a ZB-Semi volatiles column, $30 \mathrm{~m}$ long $\times 0.25 \mathrm{~mm}$ i.d. $\times 0.25 \mu \mathrm{m}$ film thickness (Phenomenex, Cheshire, UK). Injection $(1 \mu \mathrm{L})$ of each extract was carried out using the multi-mode inlet set at $280{ }^{\circ} \mathrm{C}$ with a total flow of $54 \mathrm{~mL} \mathrm{~min}{ }^{-1}$ and helium $\left(1 \mathrm{~mL} \mathrm{~min}{ }^{-1}\right.$ constant flow) was employed as the carrier gas. The oven temperature was held at $80^{\circ} \mathrm{C}$ for 3 mins before being ramped at $10^{\circ} \mathrm{C} \mathrm{min}^{-1}$ until $320^{\circ} \mathrm{C}$ and then held for 5 mins. The transfer line was held at $280{ }^{\circ} \mathrm{C}$ and 
ToF-MS detection was carried out with the ion source in electron impact mode with source temperature at $230{ }^{\circ} \mathrm{C}$ and a fixed emission current of $35 \mu \mathrm{A}$. The mass range measured was $m / z 50-500$ with an acquisition rate of 5.0 spectra second ${ }^{-1}$. Mass calibration was carried out after every second injection at $\mathrm{m} / z 68.9947$ and 365.9895 .

\section{Results and Discussion}

\subsection{General Physico-Chemical Properties of the Waste Materials}

The biosolids had dry solids (DS) contents of 19.5\%-19.8\%, and $\mathrm{pH}$ values of $8.4-8.6$ (Table 2), which are as expected for mechanically dewatered biosolids e.g., [20,21]. The volatile solids (VS) content of one biosolids sample (Biosolids2) was 62\%, which is typical for biosolids from mesophilic anaerobic digestion. However, the sample collected from a different source wastewater treatment plant, Biosolids 1, had a higher VS content of $73.6 \%$, indicating that the biosolids were less well stabilised during treatment compared to Biosolids2. The $\mathrm{N}$ contents of the biosolids were $4.7 \%$ and $6.0 \%$ for Biosolids2 and Biosolids1, respectively, which are typical for this treatment type. The biosolids products were also a source of other plant nutrient elements: P, K, Mg, S, Ca, Fe, Mo, Mn and B.

The concentrations of potentially toxic elements (PTEs) in Biosolids1 were less than or similar to the median concentrations for biosolids used in agriculture (Table 3), with the exception of Zn, which was $739 \mathrm{mg} \mathrm{kg}^{-1} \mathrm{DS}$, greater than the median concentration of $574 \mathrm{mg} \mathrm{kg}^{-1} \mathrm{DS}$. However, the concentrations of PTEs in Biosolids2 were generally significantly greater than the median concentrations shown in Table 3, with the exception of Pb, which had a slightly lower concentration. The concentrations of PTEs in both sources of biosolids were within acceptable limits for application to the soils under investigation in this research programme according to the Sludge Use in Agriculture Regulations [22]. However, the concentration profiles of PTEs detected in Biosolids1 indicated that this material generally had a greater contamination status compared to the Biosolids2 sample. Nevertheless, the relatively moderate PTE contents found in both sources of biosolids (Table 2) demonstrated the overall improvement in biosolids chemical quality, reflecting reduced industrial and domestic inputs, compared to historical contaminant concentration data, e.g., [2]. 
Table 2. General pysico-chemical characteristics of wastes collected for the research program (DS basis).

\begin{tabular}{|c|c|c|c|c|c|c|c|c|c|c|c|c|c|c|}
\hline & \multicolumn{2}{|c|}{ Biosolids } & \multicolumn{2}{|c|}{ CLO } & \multicolumn{2}{|c|}{ MBMA } & \multicolumn{2}{|c|}{$\overline{\text { PLA }}$} & \multirow[t]{2}{*}{ PSA } & \multirow[t]{2}{*}{ DPS } & \multicolumn{4}{|c|}{ RWW } \\
\hline & 1 & 2 & 1 & 2 & 1 & 2 & 1 & 2 & & & 1 & 2 & 3 & 4 \\
\hline DS (\%) & 19.5 & 19.8 & 76.6 & 76.8 & 96.1 & 88.7 & 89.7 & 88.8 & 99.9 & 97.2 & 89.8 & 84.6 & 87.2 & 74.6 \\
\hline VS (\%) & 73.6 & 62 & 55.8 & 56.2 & 2.4 & 6.66 & 6.84 & 5.21 & $<0.01$ & 33.7 & 96.3 & 99.4 & 99.7 & 98.8 \\
\hline $\mathrm{pH}$ & 8.4 & 8.6 & 8.3 & 8.0 & 12.7 & 12.5 & 12.3 & 12.4 & 12.5 & 7.2 & 6.1 & 5.4 & 5.8 & 5.9 \\
\hline Lime equivalent as $\mathrm{CaCO} 3(\% \mathrm{w} / \mathrm{w})$ & 6.2 & 9.7 & 9.6 & 8.4 & 39.8 & 23.1 & 40.7 & 27.7 & 85.5 & 52.1 & $<2$ & $<2$ & $<2$ & $<2$ \\
\hline Neutralising value as $\mathrm{CaO}(\% \mathrm{w} / \mathrm{w})$ & 3.5 & 5.4 & 5.4 & 4.7 & 22.2 & 12.6 & 22.8 & 15.5 & 46.8 & 29.2 & $<1$ & $<1$ & $<1$ & $<1$ \\
\hline Conductivity $\left(\mu \mathrm{S} \mathrm{cm}^{-1}\right)$ & 1670 & 1700 & 4440 & 7660 & 2150 & 2610 & 35700 & 4200 & 9810 & 1135 & 896 & 936 & 384 & 231 \\
\hline Total N (\%w/w) & 6.0 & 4.7 & 1.5 & 2.6 & $<0.01$ & 0.33 & $<0.01$ & 0.06 & 0.3 & 0.4 & 1.10 & 1.0 & 0.51 & 0.31 \\
\hline Nitrate $\mathrm{N}\left(\mathrm{mg} \mathrm{kg}^{-1}\right)$ & $<10$ & $<10$ & $<10$ & 63.8 & $<10$ & 34.9 & 15.6 & 27.0 & $<10$ & $<10$ & 26.7 & 37.8 & $<10$ & $<10$ \\
\hline Ammonium $\mathrm{N}\left(\mathrm{mg} \mathrm{kg}^{-1}\right)$ & 7104 & 6460 & 562 & 2410 & $<10$ & 34.9 & $<10$ & $<10$ & $<10$ & 29.8 & 128 & 528 & 20.7 & 26.8 \\
\hline Total P $\left(\mathrm{mg} \mathrm{kg}^{-1}\right)$ & 21300 & 30000 & 4440 & 4780 & 97600 & 125000 & 51200 & 77800 & 752 & 202 & 1730 & 185 & 287 & 962 \\
\hline Total K $\left(\mathrm{mg} \mathrm{kg}^{-1}\right)$ & 1330 & 2230 & 6740 & 11000 & 28200 & 28900 & 113000 & 121000 & 1120 & 183 & 2150 & 730 & 1130 & 799 \\
\hline Total $\mathrm{Mg}\left(\mathrm{mg} \mathrm{kg}^{-1}\right)$ & 3650 & 5940 & 5210 & 5820 & 6600 & 8400 & 32900 & 23900 & 12000 & 2140 & 1030 & 317 & 440 & 524 \\
\hline Total S $\left(\mathrm{mg} \mathrm{kg}^{-1}\right)$ & 13700 & 14200 & 4780 & 12100 & 16500 & 15100 & 26700 & 33600 & 2070 & 668 & 1060 & 414 & 17.1 & 619 \\
\hline Total $\mathrm{Ca}\left(\mathrm{mg} \mathrm{kg}^{-1}\right)$ & 41400 & 48100 & 53300 & 49500 & 274000 & 279000 & 184000 & 174000 & 484000 & 189000 & 10400 & 2820 & 2360 & 2830 \\
\hline Total Fe $\left(\mathrm{mg} \mathrm{kg}^{-1}\right)$ & 8240 & 42500 & 10400 & 12100 & 5070 & 3210 & 4630 & 6480 & 3180 & 883 & 1570 & 409 & 284 & 2230 \\
\hline Total Mo $\left(\mathrm{mg} \mathrm{kg}^{-1}\right)$ & 8.59 & 20.8 & 10.4 & 4.55 & 2.71 & 3.81 & 11.2 & 24.8 & 1.99 & $<1$ & 1.18 & $<1$ & $<1$ & $<1$ \\
\hline Total Mn $\left(\mathrm{mg} \mathrm{kg}^{-1}\right)$ & 357 & 783 & 370 & 337 & 130 & 234 & 1770 & 1800 & 201 & 85.5 & 146 & 86.6 & 78.6 & 112 \\
\hline Total B ( $\left.\mathrm{mg} \mathrm{kg}^{-1}\right)$ & 25.7 & 62.8 & 22.0 & 22.5 & 48.0 & 19.8 & 141 & 88.5 & 20.5 & 4.4 & 11.5 & 9.2 & 7.1 & 7.9 \\
\hline Water Soluble $\mathrm{Mg}\left(\mathrm{mg} \mathrm{kg}^{-1}\right)$ & 48.8 & 69.1 & 168 & 675 & 0.99 & 6.32 & 1.98 & 2.48 & 0.21 & 155 & 120 & 60.3 & 33.6 & 46.7 \\
\hline Water Soluble P $\left(\mathrm{mg} \mathrm{kg}^{-1}\right)$ & 546 & 516 & 68.8 & 52.0 & 0.71 & 45.7 & 23.2 & 1279 & 2.06 & 4.1 & 34.5 & 21.5 & 22.9 & 16.0 \\
\hline Water Soluble K ( $\left.\mathrm{mg} \mathrm{kg}^{-1}\right)$ & 509 & 1190 & 4100 & 7910 & 12700 & 24800 & 83300 & 89500 & 64.4 & 45.7 & 624 & 442 & 495 & 580 \\
\hline Water Soluble S $\left(\mathrm{mg} \mathrm{kg}^{-1}\right)$ & 519 & 426 & 2900 & 9330 & 10200 & 14700 & 20900 & 25900 & 18.1 & 397 & 567 & 205 & 65.8 & 132 \\
\hline Water Soluble $\mathrm{Ca}\left(\mathrm{mg} \mathrm{kg}^{-1}\right)$ & 247 & 433 & 997 & 4120 & 8670 & 121 & 64.4 & 19.6 & 9850 & 1210 & 728 & 321 & 70.9 & 125 \\
\hline
\end{tabular}


Table 2. Cont

\begin{tabular}{|c|c|c|c|c|c|c|c|c|c|c|c|c|c|c|}
\hline & \multicolumn{2}{|c|}{ Biosolids } & \multicolumn{2}{|c|}{ CLO } & \multicolumn{2}{|c|}{ MBMA } & \multicolumn{2}{|c|}{ PLA } & \multirow[t]{2}{*}{ PSA } & \multirow[t]{2}{*}{ DPS } & \multicolumn{4}{|c|}{ RWW } \\
\hline & 1 & 2 & 1 & 2 & 1 & 2 & 1 & 2 & & & 1 & 2 & 3 & 4 \\
\hline Total As $\left(\mathrm{mg} \mathrm{kg}^{-1}\right)$ & 4.06 & 8.49 & 6.78 & 6.54 & 3.48 & $<3$ & 3.99 & 12.2 & 3.86 & $<3$ & 9.82 & 12.1 & $<3$ & $<3$ \\
\hline Total Cd $\left(\mathrm{mg} \mathrm{kg}^{-1}\right)$ & 1.15 & 2.34 & 2.53 & 1.68 & 0.59 & 0.44 & 0.72 & 1.56 & 0.26 & 0.189 & 0.31 & 0.46 & 0.16 & 0.21 \\
\hline Total $\mathrm{Cu}\left(\mathrm{mg} \mathrm{kg}^{-1}\right)$ & 430 & 446 & 267 & 287 & 105 & 92.9 & 310 & 324 & 317 & 45.6 & 37.7 & 42.4 & 17.1 & 14.2 \\
\hline Total $\mathrm{Zn}\left(\mathrm{mg} \mathrm{kg}^{-1}\right)$ & 739 & 1930 & 551 & 615 & 340 & 430 & 1390 & 1670 & 64.1 & 2.15 & 144 & 50.2 & 25.3 & 52.0 \\
\hline Total Hg $\left(\mathrm{mg} \mathrm{kg}^{-1}\right)$ & 1.12 & 0.81 & 0.32 & 0.24 & $<0.02$ & 0.02 & $<0.02$ & 0.12 & 0.05 & 0.041 & 0.05 & $<0.02$ & $<0.02$ & $<0.05$ \\
\hline Total Ni (mg kg $\left.{ }^{-1}\right)$ & 30.5 & 127 & 44.9 & 39.1 & 6.34 & 6.99 & 12.1 & 16.8 & 16.0 & 6.35 & 2.73 & $<1$ & $<1$ & 3.36 \\
\hline Total $\mathrm{Pb}\left(\mathrm{mg} \mathrm{kg}^{-1}\right)$ & 92.6 & 107 & 191 & 201 & 36.1 & 35.7 & 14.5 & 186 & 12.9 & 18.4 & 238 & 53 & 5.95 & 15.9 \\
\hline Total $\mathrm{Cr}\left(\mathrm{mg} \mathrm{kg}^{-1}\right)$ & 42.7 & 213 & 67.6 & 32.4 & 18.1 & 18.8 & 11.0 & 31.0 & 31.5 & 28.6 & 17.8 & 18.5 & 2.09 & 4 \\
\hline Fluoride $(100: 1 \mathrm{H} 2 \mathrm{SO} 4)\left(\mathrm{mg} \mathrm{kg}^{-1}\right)$ & 151 & 456 & 47.4 & 81.1 & 370 & 118 & 145 & 131 & 286 & 32.2 & $<10$ & $<10$ & $<10$ & $<10$ \\
\hline Total Se $\left(\mathrm{mg} \mathrm{kg}^{-1}\right)$ & 4.69 & 3.82 & 0.2 & 0.42 & 1.92 & 1.66 & 3.68 & 4.77 & 0.19 & $<0.09$ & $<0.09$ & $<0.09$ & $<0.09$ & $<0.09$ \\
\hline
\end{tabular}

CLO: compost-like-output; MBMA: meat and bone meal ash; PLA: poultry litter ash; PSA: paper sludge ash, DPS: dried paper sludge; RWW: recycled wood waste.

Table 3. Median concentrations of PTEs in biosolids used in agriculture [23].

\begin{tabular}{cc}
\hline PTE & $\begin{array}{c}\text { Median concentration } \\
\mathbf{~ m g ~ k ~}^{-1} \mathbf{~ D S}\end{array}$ \\
\hline $\mathrm{Cd}$ & 1.3 \\
$\mathrm{Cr}$ & 61 \\
$\mathrm{Cu}$ & 295 \\
$\mathrm{Hg}$ & 1.2 \\
$\mathrm{Ni}$ & 30 \\
$\mathrm{~Pb}$ & 112 \\
$\mathrm{Zn}$ & 574 \\
\hline
\end{tabular}


The CLOs had similar DS contents of $76.6 \%$ for CLO1 and $76.8 \%$ for CLO2, and VS contents of 55.8\% and $56.2 \%$ for CLO1 and CLO2, respectively. These values were significantly lower than the VS contents measured for the biosolids products and were consistent with the higher degree of stabilisation achieved by composting processes, although, this may also reflect lower inputs of volatile organic matter in the organic fraction of MSW (OFMSW). The total N contents were 1.5\% DS and 2.6\% DS for CLO1 and CLO2, respectively. These values were lower than for the biosolids reflecting the lower $\mathrm{N}$ content of OFMSW feedstocks compared to sewage sludge; additionally, losses of $\mathrm{N}$ via ammonia volatilisation would be expected during the composting process. The CLOs were also a source of other plant nutrients, in particular they were a significant source of $\mathrm{K}$, containing $0.67 \% \mathrm{DS}$ and $1.1 \% \mathrm{DS}$ of total $\mathrm{K}$ for CLO1 and CLO2, respectively, compared to a total $\mathrm{K}$ content in the biosolids equivalent to $0.1 \%-0.2 \% \mathrm{DS}$. The concentrations of PTEs were similar to or less than those measured in the biosolids, with the exception of $\mathrm{Pb}$, which, at $191 \mathrm{mg} \mathrm{kg}^{-1}$ and $201 \mathrm{mg} \mathrm{kg}^{-1} \mathrm{DS}$ for CLO1 and CLO2, respectively, was greater than the amounts of total $\mathrm{Pb}$ measured in the biosolids, which were $92.6-107 \mathrm{mg} \mathrm{kg}^{-1} \mathrm{DS}$. The concentrations of PTEs in the CLOs were within suitable limits for agricultural application, relative to acceptable biosolids quality values (Table 3, and also see Smith [24]).

The ash materials appeared physically as dry, finely divided minerals and, as would be expected, the DS contents were large and between $88.8 \%$ for PLA2 to $99.9 \%$ for PSA. The VS contents were also small, due to the destruction of organic matter during combustion. The PSA had a VS content $<0.01 \%$; however, the VS contents of the MBMAs and PLAs were equivalent to $2.4 \%-6.8 \% \mathrm{DS}$, indicating the presence of a small residual amount of organic matter in these ash types. The $\mathrm{pH}$ values of the ash materials were alkaline and similar in the range of $\mathrm{pH} 12.3-12.7$. The PSA in particular had a high neutralising value of $46.8 \% \mathrm{w} / \mathrm{w}$, which is close to the typical value reported for agricultural lime of $50 \%-55 \% \mathrm{w} / \mathrm{w}$ [25]. The ash materials were not significant sources of $\mathrm{N}$, as this is lost to the atmosphere during combustion; however, the MBMAs and PLAs were significant sources of $\mathrm{P}$ and $\mathrm{K}$. The MBMAs contained 9.7\%-12.4\% DS of total P, and 2.8\%-2.9\% DS total K. Conversely, the PLA samples had greater K contents than P contents, equivalent to $5.1 \%$ and $7.7 \%$ DS total P and $11.2 \%$ and $12.1 \%$ total $\mathrm{K}$ for PLA1 and PLA2, respectively.

In general the concentrations of PTEs in the ashes were smaller than those in the biosolids and CLOs. However, PLA2 contained more As at $12.2 \mathrm{mg} \mathrm{kg}^{-1} \mathrm{DS}$ compared to the biosolids, CLOs and other ash materials, which contained between 3.0-8.5 mg kg-1 DS of total As. The Zn content of the PLA samples was 1390-1670 $\mathrm{mg} \mathrm{kg}^{-1} \mathrm{DS}$; this was larger than the other ash types examined and was similar to biosolids, which contained 739-1930 $\mathrm{mg} \mathrm{kg}^{-1} \mathrm{DS}$ of total $\mathrm{Zn}$. The Pb content of PLA2 was $186 \mathrm{mg} \mathrm{kg}^{-1} \mathrm{DS}$; this was also increased compared to other ash samples and was in a similar range to the CLO products, which contained 191-201 $\mathrm{mg} \mathrm{kg}^{-1} \mathrm{DS}$ of total $\mathrm{Pb}$. Theoretical calculations of the rates of PTEs applied to soil at maximum agronomic rates of ash application indicated that none of the ash materials exceeded the maximum loading rates for PTEs according to the Sludge Use in Agriculture Regulations [22]. The PTE concentrations in all the ash materials fell below the maximum compositional values for trace elements allowed in the PLA Quality Protocol [13] for the use of PLA as an agricultural fertilizer.

Three of the RWWs were classified as Grade A (RWW1, RWW3 and RWW4), and one was classified as Grade C (RWW2) according to the PAS111 Specification for the Requirement and Test Methods for Processing Waste Wood [14]. Only Grade A category materials can be used as animal bedding. Three of 
the RWW samples tested were composed of fine wood chips, including the RWW2, RWW3 and RWW4 products and RWW1 was produced from wood shavings. The materials contained moderate to small amounts of moisture and had DS contents in the range of $74.6 \%$ for RWW4 to $89.8 \%$ for RWW1. As would be expected for a cellulose/lignin-based material, the RWWs contained relatively small concentrations of plant nutrient elements. In general, the concentrations of PTEs were also relatively small compared to the other materials examined. However, RWW1 had an total concentration of $9.8 \mathrm{mg} \mathrm{kg}^{-1}$ DS, which was slightly greater than the amount of As measured in Biosolids2 (8.5 mg As kg-1 DS). The $\mathrm{Pb}$ concentration detected in the RWW1 material, equivalent to $238 \mathrm{mg} \mathrm{kg}^{-1} \mathrm{DS}$, also exceeded the concentrations of this element present in the CLO samples tested (191-201 $\mathrm{mg} \mathrm{Pb} \mathrm{kg}^{-1} \mathrm{DS}$ ).

The kiln-dried paper sludge (DPS) had a high DS content of $97.2 \%$, a VS content of $33.7 \%$ and a neutral $\mathrm{pH}$ value of 7.2. As might be expected for material derived from wood, it was not a significant source of plant nutrient elements with concentrations of $\mathrm{N}, \mathrm{P}, \mathrm{K}, \mathrm{Mg}$ and $\mathrm{S}$ in the same range, or similar to the RWWs. The concentrations of PTEs were low and similar to those observed for the PSA.

\subsection{Polychlorinated Dibenzo-p-dioxin (PCDD), Polychlorinated Dibenzofuran (PCDF) and Polychlorinated Biphenyl (PCB) Concentrations}

The greatest $\sum \mathrm{WHO}_{2005}$-TEQ value for PCDD/Fs was measured for MBMA1, at $83.1 \mathrm{ng} \mathrm{kg}^{-1} \mathrm{DS}$ (Table 4), more than 32 times the median ambient concentration in rural UK soils (2.42 ng WHO1998-TEQ $\mathrm{kg}^{-1}$ dry soil (ds), Table 5), and 14 times greater than the concentration in urban UK soils (5.92 $\mathrm{ng}$ $\mathrm{WHO}_{1998-\mathrm{TEQ} \mathrm{kg}}{ }^{-1} \mathrm{ds}$, Table 5). The remainder of the $\mathrm{WHO}_{2005}$-TEQ values were less than $20 \mathrm{ng} \mathrm{kg}^{-1}$ DS, with the exception of RWW1, which had a $\mathrm{WHO}_{2005}$-TEQ value of $26.3 \mathrm{ng} \mathrm{kg}^{-1} \mathrm{DS}$. PCDD/Fs are typically found in wood treated with the preservative pentachlorophenol (PCP) [26], which may explain the presence of PCDD/Fs in RWW1. The PAS111 [14] requires that RWW is visually inspected for contaminated wood, however, simple visual inspection cannot guarantee the detection and removal of contaminated material. Interestingly, although RWW1 was classified as a Grade A recycled wood, it had greater PCDD/F concentrations than RWW2, a Grade C material.

The lowest $\mathrm{WHO}_{2005}$-TEQ values were detected for PSA, PLA1, and RWW4 with upper bound values of $0.12 \mathrm{ng} \mathrm{kg}^{-1} \mathrm{DS}, 0.91 \mathrm{ng} \mathrm{kg}{ }^{-1} \mathrm{DS}$, and $1.33 \mathrm{ng} \mathrm{kg}^{-1} \mathrm{DS}$, respectively, lower than the median concentrations found in UK soils (Table 5). The $\mathrm{WHO}_{2005}$-TEQ values for both biosolids samples were similar, although Biosolids2 had a slightly greater value of $12.4 \mathrm{ng} \mathrm{kg}^{-1}$ DS compared to $10.5 \mathrm{ng} \mathrm{kg}^{-1} \mathrm{DS}$ for Biosolids1. The $\sum \mathrm{PCDD} / \mathrm{F}$ concentrations in the biosolids materials were $433-558 \mathrm{ng} \mathrm{kg}^{-1} \mathrm{DS}$, which were significantly smaller than the historical mean concentration for sewage sludge reported by Smith [7] of $2178 \mathrm{ng} \mathrm{kg}^{-1} \mathrm{DS}$. The upper bound WHO2005-TEQ of 10.5-12.4 $\mathrm{ng} \mathrm{kg}^{-1} \mathrm{DS}$ in the biosolids was approximately four times that of the median ambient dioxin concentration in rural UK soils of $2.42 \mathrm{ng}$ $\mathrm{WHO}_{1998}$-TEQ $\mathrm{kg}^{-1} \mathrm{ds}$, and approximately twice the median dioxin concentration of $5.92 \mathrm{ng}$ $\mathrm{WHO}_{1998}$-TEQ $\mathrm{kg}^{-1}$ ds for urban soils. Of the two CLOs, CLO1 had the greatest $\mathrm{WHO}_{2005}-\mathrm{TEQ}$ of $18.2 \mathrm{ng} \mathrm{kg}^{-1} \mathrm{DS}$ compared to $11.2 \mathrm{ng} \mathrm{kg}^{-1} \mathrm{DS}$ for CLO2. 
Table 4. Polychlorinated dibenzo- $p$-dioxins/dibenzofurans (PCDD/DF) concentrations in the waste samples (DS basis).

\begin{tabular}{|c|c|c|c|c|c|c|c|c|c|c|c|c|c|}
\hline & \multicolumn{2}{|c|}{ Biosolids } & \multicolumn{2}{|c|}{ CLO } & \multicolumn{2}{|c|}{ МВMА } & \multicolumn{2}{|c|}{ PLA } & \multirow[t]{2}{*}{ PSA } & \multicolumn{4}{|c|}{ RWW } \\
\hline & 1 & 2 & 1 & 2 & 1 & 2 & 1 & 2 & & 1 & 2 & 3 & 4 \\
\hline \multicolumn{14}{|c|}{ ng kg-1 DS } \\
\hline $2,3,7,8-\mathrm{TCDD}$ & 0.28 & 0.68 & 0.25 & 0.26 & 10.2 & 0.39 & 0.09 & 1.23 & $<0.02$ & 0.29 & 0.35 & 0.03 & 0.04 \\
\hline 1,2,3,7,8-PeCDD & 1.4 & 2.56 & 1.02 & 1.05 & 35.4 & 1.66 & $<0.35^{\mathrm{a}}$ & 4.55 & $<0.03$ & 1.27 & 0.71 & $0.33 \mathrm{i}$ & 0.11 \\
\hline 1,2,3,4,7,8-HxCDD & 1.12 & 2.26 & 1.96 & 1.39 & 27.5 & 2.14 & 0.21 & 4.28 & $<0.05$ & 2.80 & 1.87 & 0.18 & 0.16 \\
\hline 1,2,3,6,7,8-HxCDD & 13.2 & 12.4 & 19.4 & 8.16 & 53.8 & 5.02 & 0.56 & 10.1 & 0.03 & 26.0 & 13.9 & 1.75 & 1.34 \\
\hline 1,2,3,7,8,9-HxCDD & 4.36 & 5.25 & 6.66 & 3.87 & 36.8 & 3.51 & 0.30 & 6.81 & $<0.03$ & 7.12 & 3.22 & 0.62 & 0.48 \\
\hline 1,2,3,4,6,7,8-HpCDD & 441 & 269 & 986 & 460 & 270 & 43.2 & 3.00 & 72.8 & $<0.6$ & $1190^{\mathrm{b}}$ & 608 & 68.9 & 45.0 \\
\hline OCDD & $1990^{\mathrm{b}}$ & $1170^{\mathrm{b}}$ & $3250^{\mathrm{b}}$ & $3300^{\mathrm{b}}$ & 256 & 76.2 & 6.88 & 182.4 & $<2.82$ & $16500^{b}$ & $11100^{b}$ & $1170^{\mathrm{b}}$ & 644 \\
\hline $2,3,7,8-\mathrm{TCDF}$ & 4.01 & 5.48 & 2.92 & 3.32 & 37.4 & 1.91 & 0.58 & 5.99 & $<0.06$ & 1.14 & 0.87 & 0.28 & 0.26 \\
\hline $1,2,3,7,8-\mathrm{PeCDF}$ & 1.29 & 3.76 & 2.28 & 2.36 & 27.0 & 2.81 & $0.41^{\mathrm{a}}$ & 4.12 & $<0.07$ & 0.81 & 0.60 & 0.14 & 0.15 \\
\hline 2,3,4,7,8-PeCDF & 1.86 & 4.48 & 3.63 & 3.16 & 35.3 & 4.46 & $0.40^{\mathrm{a}}$ & 5.78 & $<0.07$ & 1.47 & 0.80 & 0.21 & 0.26 \\
\hline $1,2,3,4,7,8-\mathrm{HxCDF}$ & 2.19 & 5.75 & 3.38 & 3.74 & 18.5 & 4.36 & 0.33 & 2.78 & $<0.07$ & 4.47 & 2.54 & 0.41 & 0.36 \\
\hline 1,2,3,6,7,8-HxCDF & 1.9 & 4.89 & 2.96 & 2.89 & 23.3 & 5.43 & 0.36 & 3.51 & $<0.04$ & 3.36 & 1.63 & 0.31 & 0.26 \\
\hline 1,2,3,7,8,9-HxCDF & 0.23 & 0.61 & 0.17 & 0.31 & 1.99 & 0.60 & 0.04 & 0.21 & $<0.01$ & 0.27 & 0.15 & 0.11 & 0.03 \\
\hline $2,3,4,6,7,8-\mathrm{HxCDF}$ & 2.44 & 5.28 & 4.48 & 4.21 & 28.4 & 9.58 & 0.62 & 4.03 & $<0.05$ & 5.59 & 2.49 & 0.50 & 0.35 \\
\hline $1,2,3,4,6,7,8-\mathrm{HpCDF}$ & 27.0 & 35.4 & 27.6 & 46.3 & 40.8 & 18.7 & 1.07 & 7.49 & 0.13 & 209 & 122 & 14.0 & 12.4 \\
\hline $1,2,3,4,7,8,9-\mathrm{HpCDF}$ & 1.61 & 4.08 & 2.00 & 2.43 & 7.17 & 5.56 & 0.20 & 0.99 & $<0.05$ & 10.29 & 6.31 & 0.77 & 0.58 \\
\hline OCDF & 54.2 & 71.3 & 58.6 & 79.4 & 11.0 & 12.8 & 2.81 & 5.17 & $<0.76$ & 812 & 500 & 42.9 & 27.9 \\
\hline Sum TEQ ${ }^{\mathrm{c}}$ lower & 10.5 & 12.4 & 18.2 & 11.2 & 83.1 & 7.43 & 0.57 & 12.3 & $<0.01$ & 26.3 & 14.8 & 2.05 & 1.33 \\
\hline Sum TEQ ${ }^{\mathrm{c}}$ upper & 10.5 & 12.4 & 18.2 & 11.2 & 83.1 & 7.43 & 0.91 & 12.3 & 0.12 & 26.3 & 14.8 & 2.05 & 1.33 \\
\hline Sum $^{\mathrm{d}}$ & 2550 & 1610 & 4370 & 3920 & 920 & 198 & 18.2 & 322 & 4.89 & 18800 & 12300 & 1310 & 733 \\
\hline
\end{tabular}

a Indicative due to analyze suppression on instrument; ${ }^{\mathrm{b}}$ indicative out of linear range; ${ }^{\mathrm{c}} \mathrm{WHO}_{2005}-\mathrm{TEQ} ;{ }^{\mathrm{d}}$ concentration of congeners $<$ limit of detection (LOD) assumed to LOD CLO,

compost-like-output; MBMA, meat and bone meal ash; PLA, poultry litter ash; PSA, paper sludge ash; RWW, recycled waste wood. 
Table 5. Median concentrations of organic contaminants in UK soils ( $\mu \mathrm{g} \mathrm{kg}^{-1}$ dry soil (ds)), except where indicated.

\begin{tabular}{|c|c|c|c|}
\hline Compound & Area & Median/50 Percentile & 95 Percentile \\
\hline \multirow[t]{2}{*}{$\mathrm{PCDD} / \mathrm{F}$} & Rural (UK) & $2.42 \mathrm{ng} \mathrm{WHO}_{1998}-\mathrm{TEQ} \mathrm{kg}^{-1 \mathrm{a}}$ & $18.0 \mathrm{ng} \mathrm{WHO}_{1998}-\mathrm{TEQ}_{\mathrm{kg}}{ }^{-1 \mathrm{a}}$ \\
\hline & Urban (UK) & $5.92 \mathrm{ng} \mathrm{WHO}_{1998}-\mathrm{TEQ} \mathrm{kg}^{-1 \mathrm{~b}}$ & \\
\hline \multirow[t]{2}{*}{ PCBs (Sum of total) } & Rural (UK) & $1.01^{\mathrm{a}}$ & $5.51^{\mathrm{a}}$ \\
\hline & Urban (UK) & $1.86^{\mathrm{c}}$ & \\
\hline PAHs & Rural (UK) & $2240^{\mathrm{a}}$ & $7503^{a}$ \\
\hline \multirow{2}{*}{ PAHs (Sum 4) } & Rural (UK) & $296.4^{\mathrm{d}}$ & \\
\hline & Urban (UK) & $1433^{\mathrm{d}}$ & \\
\hline
\end{tabular}

The chemical analysis results were based on single samples of each waste material. These were representative of the batch of waste collected for inclusion in the subsequent experimental programme and therefore provide a good indication of the general patterns of contamination that are likely to be found in these waste streams. However, the statistical variation in the concentrations of PCDD/Fs, and of the other compounds analysed, for each waste stream was not determined. The wider aim of this study was to investigate the transfer of contaminants from specific controlled batches of waste to the food chain in studies with crops and dairy cattle; therefore, the key objective here was to quantify the concentrations of contaminants in each batch of collected waste material to be used in crop and milk transfer investigations. Further work is necessary to complete a survey and statistical sampling programme to determine the variability of key compounds of interest in different waste streams, but this was beyond the remit of, and resources available to, the project.

The PCDD/F concentrations in the materials were generally significantly lower than European limits and proposed limit values for these compounds in biosolids, compost and PLA (Table 6). For example, the concentrations in biosolids were approximately 10 times smaller than the proposed EC limit for PCDD/Fs in biosolids of $100 \mathrm{ng}$ TEQ $\mathrm{kg}^{-1}$ DS [31]. However, more recent limits set for PCDD/Fs in materials applied to agricultural land have adopted a more conservative approach. For example, the limit stipulated in the UK PLA Quality Protocol is an average of $10 \mathrm{ng} \mathrm{WHO}_{2005}-\mathrm{TEQ} \mathrm{kg}^{-1}$ DS for 10 samples (Table 6). There is no consistent approach to the statutory measures introduced on organic contaminants across Europe for biosolids [7], and some countries, such as the UK, USA and Canada have argued there is no technical case for regulating limits on organic contaminants in biosolids for agricultural application. This is because the growing body of scientific investigation and risk assessment consistently show that the human food chain and the environment are not at risk from the concentrations of organic contaminants present in biosolids [32-36]. For example, a recent risk assessment on the use of sewage sludge as a fertilizer and soil conditioner by the Norwegian Scientific Committee for Food Safety (VKM), which included a pathway analysis of the risks to human health from organic contaminants via crops and meat, reached a similar conclusion [36]. Nevertheless, data limitations restricted the number of contaminants that could be examined in the risk assessment, and whereas PCBs and PAHs were amongst the groups assessed, other potentially important types, such as PBDEs and PCDD/Fs for instance, were excluded. Consequently, there is a need to update and expand the risk assessments on the agricultural use of biosolids to maintain confidence and assurance about food safety. In future, as knowledge about the toxicity of 
various groups of organic contaminants improves, food regulators are likely to take a more rigorous approach to assessing the risk to human health from organic contaminants when biosolids and other wastes are used in agriculture.

Table 6. Standards and proposed standards for maximum concentrations of selected organic contaminants in biosolids [7], compost [37] and PLA [13] compared to concentrations found in this study.

\begin{tabular}{|c|c|c|c|c|}
\hline & & 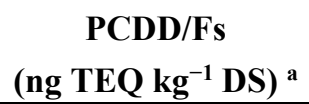 & $\begin{array}{c}\text { PCBs } \\
\left(\mathrm{mg} \mathrm{kg}^{-1} \mathrm{DS}\right)\end{array}$ & $\begin{array}{c}\text { PAHs } \\
\left(\mathrm{mg} \mathrm{kg}^{-1} \mathrm{DS}\right)\end{array}$ \\
\hline \multirow[t]{8}{*}{ Biosolids } & $\mathrm{EC}[31]^{\mathrm{b}}$ & 100 & $0.8^{\mathrm{c}}$ & $6^{d}$ \\
\hline & Denmark & & & $3^{d}$ \\
\hline & Sweden & & $0.4^{\mathrm{c}}$ & $3^{e}$ \\
\hline & Lower Austria & 100 & $0.2^{f}$ & \\
\hline & Germany & $100^{\mathrm{g}}$ & $0.2^{\mathrm{d}}$ & \\
\hline & France & & $0.8^{c}$ & \\
\hline & Biosolids1 & 11 & $0.019^{c}$ & $0.41^{\mathrm{h}}$ \\
\hline & Biosolids2 & 12 & $0.047^{\mathrm{c}}$ & $0.72^{\mathrm{h}}$ \\
\hline \multirow[t]{10}{*}{ Compost } & Saveyn and Eder [37] ${ }^{\mathrm{i}}$ & $30^{g}$ & $0.2\left(\mathrm{PCB}_{7}\right)$ & $6\left(\mathrm{PAH}_{16}\right)^{\mathrm{j}}$ \\
\hline & Austria & $20^{\mathrm{g}}$ & $0.2\left(\mathrm{PCB}_{6}\right)$ & 6 \\
\hline & Belgium & & $0.8\left(\mathrm{PCB}_{6}\right)$ & \\
\hline & Germany & $\mathrm{k}$ & $\mathrm{k}$ & \\
\hline & France & & $0.8\left(\mathrm{PCB}_{6}\right)$ & \\
\hline & Luxembourg & $20^{\mathrm{gl}}$ & $0.1^{1}$ & $10\left(\mathrm{PAH}_{16}\right)^{\mathrm{jl}}$ \\
\hline & Slovenia & & 0.4 (1st class); 1 (2nd class $\left.\mathrm{PCB}_{6}\right)$ & 3 \\
\hline & Switzerland & $20^{\mathrm{gl}}$ & & $4\left(\mathrm{PAH}_{16}\right)^{\mathrm{jl}}$ \\
\hline & CLO1 & 18 & $0.017^{\mathrm{c}}$ & $0.18^{\mathrm{h}}$ \\
\hline & $\mathrm{CLO} 2$ & 11 & $0.016^{\mathrm{c}}$ & $0.11^{\mathrm{h}}$ \\
\hline \multirow[t]{6}{*}{ PLA } & UK Quality Protocol [13] & $20^{\mathrm{m}} ; 10^{\mathrm{n}}$ & & \\
\hline & MBMA1 & 83 & $0.0003^{c}$ & $0.001^{\mathrm{h}}$ \\
\hline & MBMA2 & 7.4 & $0.002^{c}$ & $0.023^{h}$ \\
\hline & PLA1 & 0.91 & $0.0004^{c}$ & $0.017^{\mathrm{h}}$ \\
\hline & PLA2 & 12 & $0.0004^{c}$ & $0.097^{\mathrm{h}}$ \\
\hline & PSA & 0.12 & $0.0004^{c}$ & $0.0003^{\mathrm{h}}$ \\
\hline
\end{tabular}

$\mathrm{PCDD} / \mathrm{Fs}$, polychlorinated dibenzo-p-dioxins and dibenzofurans; PCBs, polychlorinated biphenyls; PAHs, polycyclic aromatic hydrocarbons; CLO, compost-like-output; MBMA, meat and bone meal ash; PLA, poultry litter ash; PSA, paper sludge ash; ${ }^{\text {a }}$ Unless specified TEQ system (I-TEQ, $\mathrm{WHO}_{1998}-\mathrm{TEQ}, \mathrm{WHO}_{2005}$-TEQ) not reported; ${ }^{b}$ proposed limit value; ${ }^{\mathrm{c}}$ Sum of ICES 7 (PCB 28, 52, 101, 118, 138, 153, 180); ${ }^{\mathrm{d}}$ Sum of nine congeners (acenapthene, fluorene, phenanthrene, fluoranthene, pyrene, benzo[ $b+j+k]$ fluoranthene, benzo $[a]$ pyrene, benzo $[g h i]$ perylene, indeno[1,2,3-c, $d]$ pyrene); ${ }^{\mathrm{e}}$ Sum of six congeners; ${ }^{\mathrm{f}}$ Each of six congeners (PCB 28, 52, 101，138，153, 180); ' I-TEQ; ${ }^{\mathrm{h}} \mathrm{PAH}_{4}$ (benz[ $a$ ] anthracene, chrysene, benzo[b]fluoranthene , benzo[a]pyrene); ${ }^{\mathrm{i}}$ Proposed end of waste criteria for compost and digestate; ${ }^{\mathrm{j}} 16 \mathrm{PAHs}$ listed in the US EPA priority pollutant list [38]; ${ }^{\mathrm{k}}$ maximum sum of PCDD/F and dl-PCB $=30 \mathrm{ng}$ WHO-TEQ $\mathrm{kg}^{-1} \mathrm{D}$, in some cases additional restrictions for PCDD/F of $5 \mathrm{ng}$ WHO-TEQ kg ${ }^{-1} \mathrm{DM}$; ${ }^{1}$ guide value; ${ }^{\mathrm{m}}$ maximum (ng WHO${ }_{2005}-\mathrm{TEQ} \mathrm{kg}^{-1}$ ); ${ }^{\mathrm{n}}$ average for each 10 samples or each shipment (ng $\mathrm{WHO}_{2005}$-TEQ $\mathrm{kg}^{-1}$ ). 
The concentration in MBMA1 exceeded the maximum limit in the PLA Quality Protocol [13] of $20 \mathrm{ng} \mathrm{WHO}_{2005}$-TEQ $\mathrm{kg}^{-1}$ DS by approximately 4 times, and the limit for an average of 10 samples, of $10 \mathrm{ng} \mathrm{WHO}_{2005}$-TEQ $\mathrm{kg}^{-1} \mathrm{DS}$, by approximately 8 times. Differences in the mode of operation of incineration processes between biomass combustion plants are likely to be a major source of variation in the chemical composition of residual ash products [39]. However, it should be noted that the analytical results presented here may only provide an indicative measure of the compositional properties of the waste products examined, and do not test the statistical variability and characteristics of the materials.

The dominant dioxin congener in the waste materials was OCDD, present in indicative concentrations between $1170-1990 \mathrm{ng} \mathrm{kg}^{-1}$ DS in the biosolids samples and RWW3, 3250-3300 $\mathrm{ng} \mathrm{kg}^{-1}$ DS in the CLOs, and $16500 \mathrm{ng} \mathrm{kg}^{-1} \mathrm{DS}$ and $11100 \mathrm{ng} \mathrm{kg}^{-1}$ DS for RWW1 and RWW2, respectively.

Additionally, 1,2,3,4,6,7,8-HpCDD was found at a concentration of $1190 \mathrm{ng} \mathrm{kg}^{-1}$ DS for RWW1, and was also present in relatively high concentrations in the range: $269-986 \mathrm{ng} \mathrm{kg}^{-1} \mathrm{DS}$ in several other materials (Biosolids2, MBMA1, Biosolids1, CLO2, RWW2 and CLO2). PCDFs found in relatively high concentrations were the related congeners: $\mathrm{OCDF}$ and 1,2,3,4,6,7,8-HpCDF. The greatest concentrations of OCDF were found in RWW1 and RWW2, at 812 and $500 \mathrm{ng} \mathrm{kg}^{-1} \mathrm{DS}$, respectively.

The largest $\sum \mathrm{WHO}_{2005}$-TEQ values obtained for (dioxin-like) non-Ortho PCBs (PCBs 77, 81, 126 and 169) were measured in the biosolids and were $1.07 \mathrm{ng} \mathrm{kg}^{-1} \mathrm{DS}$ and $1.66 \mathrm{ng} \mathrm{kg}^{-1} \mathrm{DS}$ for Biosolids1 and Biosolids2, respectively, and for MBMA1 the TEQ was $1.68 \mathrm{ng} \mathrm{kg}^{-1}$ DS (Table 7). The congener present in the greatest concentrations was PCB77, at 255-264 ng kg-1 DS in CLO, and 192-239 $\mathrm{ng} \mathrm{kg}^{-1} \mathrm{DS}$ in biosolids (Table 7). Additionally, PCB77 was present at relatively high concentrations in RWW in the range $81-108 \mathrm{ng} \mathrm{kg}^{-1} \mathrm{DS}$.

For the Ortho-PCBs (Table 8), the greatest values for the $\sum$ ICES 6 congeners $(28,52,101,153,138$, and 180) (which are all non-dioxin like PCBs) [13] were measured in the biosolids samples and were $41.0 \mu \mathrm{g} \mathrm{kg}^{-1}$ DS for Biosolids2 and $17.3 \mu \mathrm{g} \mathrm{kg}^{-1} \mathrm{DS}$ for Biosolids1. The CLOs also had relatively high values of $\sum$ ICES 6 , equivalent to $15.7-17.1 \mu \mathrm{g} \mathrm{kg}-1$ DS, and similar values were present in samples of RWW, 11.2-17.1 $\mu \mathrm{g} \mathrm{kg}^{-1} \mathrm{DS}$. The $\sum \mathrm{WHO}_{2005}$-TEQ values for the dioxin-like ortho PCBs (PCBs 105, $114,118,123,156,167$ and 189) were relatively small and in the range $0.004 \mathrm{ng} \mathrm{kg}^{-1}$ (MBMA1, MBMA2, PLA1 and PLA2) to $0.29 \mathrm{ng} \mathrm{kg}^{-1} \mathrm{DS}$ (Biosolids2). For those waste types that contained greater concentrations of PCBs (biosolids, CLOs and RWW1 and 2), a number of congeners were generally present in concentrations greater than $1 \mathrm{ng} \mathrm{kg}^{-1} \mathrm{DS}$, but less than $10 \mathrm{ng} \mathrm{kg}^{-1} \mathrm{DS}$; these included the following 10 congeners: PCB18, PCB28, PCB31, PCB47, PCB49, PCB52, PCB101, PCB118, PCB138, PCB153 and PCB180. The other eight congeners, PCB51, PCB105, PCB123, PCB128, PCB156, PCB157, $\mathrm{PCB} 167$ and $\mathrm{PCB} 189$, tended to be present in concentrations $<1 \mathrm{ng} \mathrm{kg}^{-1} \mathrm{DS}$.

The findings indicated that the concentrations of PCDD/Fs and PCBs in representative, contemporary waste materials used in agriculture were generally relatively low, and for several of the waste materials the concentrations were within the range found in UK soils, and that they were generally considerably smaller than previously reported results from historical surveys of biosolids and CLO materials. In comparison to these historical data, the results demonstrated the beneficial impact on, and reduction in, the concentrations of PCDD/Fs and PCBs in different waste-derived materials of source controls introducing in the 1980s-1990s to significantly reducing the primary emissions of these contaminants to the environment [5]. 
Elskens et al. [40] measured the dioxin contents in various fertilizer products in Belgium, and found that the median PCDD/F and dioxin-like PCB concentrations for sewage sludge (16 samples) and compost (15 samples of either composted plant material or waste) spread on agricultural land in Belgium were 10.5 and $11.1 \mathrm{ng}$ TEQ $\mathrm{kg}-1$, respectively. These values were generally in a similar range to, albeit slight less than, the results for total PCDD/Fs and dioxin-like PCBs of 11.7-14.3 and 12.0-19.0 ng TEQ kg-1, respectively, for biosolids and CLO found in this investigation. Elskens et al. [40] calculated that the annual input of dioxins due to fertilizer use at the country level was equivalent to $5.45 \mathrm{~g}^{\text {TEQ year }}{ }^{-1}$ from which $49 \%$ are supplied by manure, $12 \%$ by chemical fertilisers, $12 \%$ by sewage sludge, $4 \%$ by liming materials and $12 \%$ by compost. This compared to a total atmospheric deposition on agricultural soils equivalent to approximately 33.6 g TEQ year ${ }^{-1}$, which was approximately 6 times greater than the total input from fertilizer materials. Fertilization with compost containing PCDD/Fs at the maximum regulatory limit resulted in an input of $10.38 \mathrm{ng}^{\mathrm{TEQ} \mathrm{m}^{-2}}$ year $^{-1}$, nearly 30 times greater than soil receiving conventional fertilizer $\left(0.38 \mathrm{ng}\right.$ TEQ $\mathrm{m}^{-2}$ year $\left.^{-1}\right)$. Nevertheless, the dioxin input to soil remained below the maximum tolerable input of $20.82 \mathrm{ng}$ TEQ $\mathrm{m}^{-2}$, estimated in a study conducted by Dumortier et al. [41], to prevent harmful dietary intakes of dioxins. Overall, therefore, the concentrations of PCDD/Fs and dioxin-like PCBs present in waste materials spread to land may represent a smaller contamination risk compared to other sources, such as atmospheric deposition [40].

Table 7. Non-ortho polychlorinated biphenyl (PCB) concentrations in waste samples (DS basis).

\begin{tabular}{|c|c|c|c|c|c|c|c|c|c|c|c|c|c|}
\hline & \multicolumn{2}{|c|}{ Biosolids } & \multicolumn{2}{|c|}{ CLO } & \multicolumn{2}{|c|}{ МВМА } & \multicolumn{2}{|c|}{ PLA } & \multirow[t]{2}{*}{ PSA } & \multicolumn{4}{|c|}{ RWW } \\
\hline & 1 & 2 & 1 & 2 & 1 & 2 & 1 & 2 & & 1 & 2 & 3 & 4 \\
\hline \multicolumn{14}{|c|}{ ng kg ${ }^{-1} \mathrm{DS}$} \\
\hline PCB 77 & $192^{a}$ & $239^{a}$ & 264 & 255 & 25.7 & 4.23 & 4.23 & 9.73 & 3.11 & 108 & 81.3 & 17.3 & 42.8 \\
\hline PCB 81 & $7.81^{a}$ & $9.01^{\mathrm{a}}$ & 12.8 & 11.6 & 5.36 & $<0.52$ & $<0.47$ & 1.28 & $<0.42$ & 5.89 & 4.13 & $0.83 \mathrm{i}$ & 2.19 \\
\hline PCB 126 & 9.87 & $15.6^{\mathrm{a}}$ & 6.5 & 7.1 & 15.4 & 0.69 & 0.33 & 3.24 & $<0.15$ & 3.6 & 1.77 & 0.86 & 1.19 \\
\hline PCB 169 & 1.95 & 2.39 & 1.1 & 1.2 & 4.51 & 0.35 & $0.57^{\mathrm{a}}$ & 1.09 & $<0.51$ & 0.33 & 0.2 & 0.15 & $<0.35$ \\
\hline $\mathrm{TEQ}^{\mathrm{b}}$ lower & 1.07 & 1.66 & 0.72 & 0.77 & 1.68 & 0.08 & 0.03 & 0.36 & $<0.01$ & 0.38 & 0.19 & 0.09 & 0.12 \\
\hline $\mathrm{TEQ}^{\mathrm{b}}$ upper & 1.07 & 1.66 & 0.72 & 0.77 & 1.68 & 0.08 & 0.06 & 0.36 & 0.03 & 0.38 & 0.19 & 0.09 & 0.13 \\
\hline Total & 212 & 266 & 84.1 & 275 & 50.9 & 5.78 & 5.6 & 15.4 & 4.19 & 118 & 87.4 & 19.2 & 46.5 \\
\hline
\end{tabular}

\subsection{Polybrominated Dibenzo-p-dioxin (PBDD), Dibenzofuran (PBDF) and Polybrominated Biphenyl} (PBB) Concentrations

The total concentrations of the $11 \mathrm{PBDD} / \mathrm{Fs}$ measured in the biosolids samples were 2300 and $4410 \mathrm{ng} \mathrm{kg}{ }^{-1}$ DS for Biosolids1 and Biosolids2, respectively (Table 9). Venkatesan and Halden [41] analysed 12 PBDD/Fs in composited archived biosolids that were collected in 32 US States and the District of Columbia from 94 wastewater treatment plants as part of the US EPA national sewage sludge survey in 2001. Two PBDDs and five PBDFs were detected in the biosolids (all of which were detected in the present study), with a total mean concentration of $10,000 \mathrm{ng} \mathrm{kg}^{-1}$ DS (range 630-42,800); this was approximately 2-4 times greater than the total concentrations found in the biosolids samples measured here, reflecting 
differences in emission patterns of these compounds in the US compared to the contemporary UK environment. However, the $\mathrm{WHO}_{2005}$-TEQ values were $40.3 \mathrm{ng} \mathrm{kg}{ }^{-1} \mathrm{DS}$ for Biosolids1 and $78.0 \mathrm{ng} \mathrm{kg}^{-1}$ DS for Biosolids2 (Table 9), and were similar to the mean $\mathrm{WHO}_{2005}$-TEQ contribution observed by Venkatesan and Haldan [41] of $72 \mathrm{ng} \mathrm{kg}^{-1}$ for archived US biosolids samples from 2001.

Table 8. Ortho-polychlorinated biphenyl (PCB) concentrations in waste samples (DS basis).

\begin{tabular}{|c|c|c|c|c|c|c|c|c|c|c|c|c|c|}
\hline & \multicolumn{2}{|c|}{ Biosolids } & \multicolumn{2}{|c|}{ CLO } & \multicolumn{2}{|c|}{ МВМА } & \multicolumn{2}{|c|}{ PLA } & \multirow[t]{2}{*}{ PSA } & \multicolumn{4}{|c|}{ RWW } \\
\hline & 1 & 2 & 1 & 2 & 1 & 2 & 1 & 2 & & 1 & 2 & 3 & 4 \\
\hline & \multicolumn{13}{|c|}{$\left(\mu \mathrm{g} \mathrm{kg}{ }^{-1} \mathrm{DS}\right)$} \\
\hline PCB18 & 1.85 & 6.22 & 3.69 & 1.76 & $<0.05$ & 0.19 & $<0.08$ & $<0.07$ & $<0.07$ & 2.31 & 4 & $<0.05$ & 0.52 \\
\hline PCB28 & 2.64 & 6.07 & 3.94 & 2.15 & $<0.08$ & $1.34^{\mathrm{a}}$ & 0.12 & 0.2 & $<0.11$ & 2.52 & 3.22 & 0.75 & 0.66 \\
\hline PCB31 & 2.15 & 7.55 & 4.06 & 2.28 & 0.08 & $0.53^{\mathrm{a}}$ & $<0.12$ & 0.09 & $<0.11$ & 2.61 & 3.22 & 0.6 & 0.7 \\
\hline PCB47 & 1.36 & 1.61 & 0.8 & 0.64 & 0.03 & $0.24^{\mathrm{a}}$ & $<0.08$ & 0.02 & $<0.07$ & 0.35 & 0.31 & 0.11 & 0.12 \\
\hline PCB49 & 1.47 & 2.87 & 1.62 & 1.18 & $<0.04$ & $0.17^{\mathrm{a}}$ & $<0.07$ & $<0.06$ & $<0.06$ & 0.92 & 0.84 & 0.19 & 0.13 \\
\hline PCB51 & 0.23 & 0.32 & 0.13 & 0.08 & $<0.01$ & $<0.01$ & $<0.02$ & $<0.01$ & $<0.02$ & 0.09 & 0.09 & 0.02 & 0.03 \\
\hline PCB52 & 3.24 & 8.46 & 3.24 & 2.27 & $<0.05$ & 0.32 & $<0.09$ & $<0.07$ & $<0.08$ & 1.63 & 1.26 & 0.41 & 0.77 \\
\hline РCB99 & 1.04 & 2.55 & 0.73 & 0.63 & $<0.02$ & $0.03^{\mathrm{a}}$ & $<0.04$ & 0.02 & $<0.04$ & 0.53 & $0.24^{\mathrm{a}}$ & 0.15 & 0.2 \\
\hline PCB101 & 2.63 & 7.39 & 2.31 & 2.15 & 0.04 & 0.07 & $<0.07$ & $<0.06$ & $<0.06$ & 1.92 & 0.96 & 0.54 & 0.59 \\
\hline PCB105 & 0.78 & 2.34 & 0.77 & 0.74 & 0.02 & 0.02 & 0.03 & 0.02 & 0.02 & 0.61 & 0.24 & 0.15 & 0.2 \\
\hline PCB114 & 0.09 & 0.1 & 0.05 & 0.04 & $<0.01$ & $<0.01$ & 0.01 & $<0.01$ & $<0.01$ & 0.03 & 0.01 & $<0.01$ & 0.01 \\
\hline PCB118 & 2.07 & 5.84 & 1.72 & 1.55 & 0.04 & 0.05 & 0.07 & 0.05 & $<0.06$ & 1.4 & 0.57 & 0.37 & 0.47 \\
\hline PCB123 & 0.05 & 0.08 & 0.04 & 0.05 & $<0.01$ & $<0.01$ & $<0.01$ & $<0.01$ & $<0.01$ & 0.04 & 0.04 & $<0.01$ & 0.01 \\
\hline PCB128 & 0.45 & 1.08 & 0.4 & 0.36 & $<0.01$ & $<0.01$ & $<0.01$ & $<0.01$ & $<0.01$ & 0.4 & 0.14 & 0.09 & 0.11 \\
\hline PCB138 & 3.58 & 8.06 & 3.05 & 3.23 & 0.05 & 0.05 & 0.07 & 0.06 & $<0.05$ & 3.76 & 1.73 & 0.93 & 0.82 \\
\hline PCB153 & 3.24 & 7.08 & 2.6 & 3.16 & 0.03 & 0.03 & 0.06 & 0.03 & $<0.05$ & 3.53 & 1.91 & 0.81 & 0.64 \\
\hline PCB156 & 0.35 & 0.82 & 0.26 & 0.26 & 0.01 & $<0.01$ & $<0.01$ & $<0.01$ & $<0.01$ & 0.32 & 0.13 & 0.08 & 0.08 \\
\hline PCB157 & 0.09 & 0.19 & 0.05 & 0.05 & $<0.01$ & $<0.01$ & $<0.01$ & $<0.01$ & $<0.01$ & 0.07 & 0.04 & 0.02 & 0.01 \\
\hline PCB167 & 0.12 & 0.3 & 0.09 & 0.1 & $<0.01$ & $<0.01$ & $<0.01$ & $<0.01$ & $<0.01$ & 0.1 & 0.05 & 0.03 & 0.03 \\
\hline PCB180 & 1.92 & 3.93 & $2.00 \mathrm{a}$ & 2.7 & 0.01 & $<0.01$ & $<0.01$ & 0.01 & $<0.01$ & 3.7 & 2.16 & 0.6 & 0.35 \\
\hline PCB189 & 0.03 & 0.09 & 0.03 & 0.05 & $<0.01$ & $<0.01$ & $<0.01$ & $<0.01$ & $<0.01$ & 0.04 & 0.02 & $<0.01$ & $<0.01$ \\
\hline$\sum \operatorname{ICES} 6^{\mathrm{b}}$ lower $^{\mathrm{c}}$ & 17.3 & 41 & 17.1 & 15.7 & 0.14 & 1.8 & 0.19 & 0.3 & $<0.01$ & 17.1 & 11.2 & 4.04 & 3.83 \\
\hline$\sum \operatorname{ICES} 6^{\mathrm{b}}$ upper $^{\mathrm{d}}$ & 17.3 & 41 & 17.1 & 15.7 & 0.27 & 1.82 & 0.41 & 0.43 & 0.36 & 17.1 & 11.2 & 4.04 & 3.83 \\
\hline$\sum \operatorname{ICES} 7^{\mathrm{e}}$ lower $^{\mathrm{c}}$ & 19.3 & 46.8 & 18.9 & 17.2 & 0.17 & 1.79 & 0.32 & 0.35 & 0 & 18.5 & 11.8 & 4.41 & 4.3 \\
\hline$\sum \operatorname{ICES} 7^{\mathrm{e}}$ upper $^{\mathrm{d}}$ & 19.3 & 46.8 & 18.9 & 17.2 & 0.3 & 1.87 & 0.49 & 0.48 & 0.42 & 18.5 & 11.8 & 4.41 & 4.3 \\
\hline TEQf (ng kg ${ }^{-1}$ ) & 0.11 & 0.29 & 0.09 & 0.09 & 0.004 & 0.004 & 0.005 & 0.004 & 0.004 & 0.08 & 0.03 & 0.02 & 0.03 \\
\hline Sum (total) & 29.4 & 73 & 29.6 & 25.4 & 0.63 & 3.22 & 1 & 0.85 & 0.88 & 26.9 & 20.9 & 5.94 & 6.47 \\
\hline
\end{tabular}

CLO, compost-like-output; MBMA, meat and bone meal ash; PLA, poultry litter ash; PSA, paper sludge ash; RWW, recycled waste wood; ${ }^{a}$ indicative; ${ }^{b}$ ICES 6 congeners: 28, 52, 101, 153, 138, and 180; ${ }^{c}$ lower bound; d, upper bound; ${ }^{\mathrm{e}}$ ICES 7 congeners: 28, 52, 101, 118, 138, 153, and 180; ${ }^{\mathrm{f}}$ Sum TEQ for dioxin-like ortho PCBs $(105,114,118,123,156,167$ and 189). 
Table 9. Polybrominated dibenzo-p-dioxin (PBDD) and dibenzofuran (PBDF) concentrations in waste samples (DS basis).

\begin{tabular}{|c|c|c|c|c|c|c|c|c|c|c|c|c|c|}
\hline & \multicolumn{2}{|c|}{ Biosolids } & \multicolumn{2}{|c|}{ CLO } & \multicolumn{2}{|c|}{ MBMA } & \multicolumn{2}{|c|}{ PLA } & \multirow[t]{2}{*}{ PSA } & \multicolumn{4}{|c|}{ RWW } \\
\hline & 1 & 2 & 1 & 2 & 1 & 2 & 1 & 2 & & 1 & 2 & 3 & 4 \\
\hline & \multicolumn{13}{|c|}{$\mathrm{ng} \mathrm{kg}^{-1} \mathrm{DS}$} \\
\hline 237-TriBDD & 0.18 & 0.23 & 0.3 & 0.26 & 0.07 & $<0.06$ & 0.01 & 0.1 & $<0.01$ & 0.04 & 0.07 & 0.05 & 0.02 \\
\hline 2378-TetraBDD & 0.1 & 0.19 & 0.28 & 0.19 & 0.07 & $<0.04$ & 0.01 & $<0.04$ & $<0.01$ & $<0.02$ & 0.03 & $<0.02$ & $<0.05$ \\
\hline 12378-PentaBDD & 2.25 & 2.67 & 1.41 & 0.87 & $<0.04$ & $<0.04$ & $<0.03$ & $<0.04$ & $<0.02$ & $<0.02$ & $<0.03$ & $<0.02$ & $<0.37$ \\
\hline 123478/123678-HexaBDD & 23.4 & 25.4 & 14.7 & 1.43 & $<0.09$ & $<0.09$ & $<0.06$ & 2.22 & $<0.06$ & $<0.04$ & $<0.05$ & $<0.04$ & $\mathrm{ab}$ \\
\hline 123789-HexaBDD & 14.9 & 15.7 & 8.49 & 0.96 & $<0.11$ & $<0.12$ & $<0.04$ & 0.95 & $<0.04$ & $<0.06$ & $<0.07$ & $<0.06$ & $\mathrm{ab}$ \\
\hline 238-TriBDF & 10.2 & 25.8 & 7.83 & 6.75 & 0.82 & 0.33 & 0.15 & 2.07 & $<0.04$ & 1.46 & 0.48 & 0.19 & $0.35 \mathrm{i}$ \\
\hline 2378-TetraBDF & 6.5 & 18.6 & 3.91 & 3.88 & 0.12 & $<0.05$ & 0.49 & 1.12 & $<0.01$ & 0.57 & 0.11 & 0.2 & 0.11 \\
\hline 12378-PentaBDF & 9.11 & 15.1 & 5.43 & 5.22 & $<0.04$ & $<0.06$ & 0.11 & 1.21 & $<0.03$ & 0.27 & $<0.06$ & $<0.07$ & $<0.16$ \\
\hline 23478-PentaBDF & 9.62 & 27.3 & 8.87 & 7.09 & $<0.07$ & $<0.08$ & 0.11 & 1.65 & $<0.04$ & 1 & 0.22 & $<0.05$ & $<0.17$ \\
\hline 123478-HexaBDF & 65.8 & 132 & 71 & 53.2 & $<0.13$ & 0.13 & 1.18 & 10.2 & $<0.12$ & 5.28 & 1.53 & $<0.15$ & $\mathrm{ab}$ \\
\hline 1234678-HeptabromoBDF & $2160^{\mathrm{bc}}$ & $4150^{\mathrm{bc}}$ & $1620^{\mathrm{c}}$ & 716 & 6.39 & $<0.13$ & 9.74 & 270 & $<1.36$ & 190 & 51.2 & 21.2 & $\mathrm{ab}$ \\
\hline $\mathrm{TEQ}^{\mathrm{d}}$ lower & 40.3 & 77.9 & 32.2 & 18 & 0.14 & 0.091 & 0.33 & 5.03 & $<0.01$ & 3 & 0.81 & 0.23 & 0.01 \\
\hline $\mathrm{TEQ}^{\mathrm{d}}$ upper & 40.3 & 77.9 & 32.2 & 18 & 0.25 & 0.25 & 0.37 & 5.11 & 0.09 & 3.05 & 0.86 & 0.33 & 0.52 \\
\hline Sum & 2300 & 4410 & 1750 & 796 & 1.13 & 289 & 11.9 & 7.93 & 22 & 53.8 & 1.73 & 0.05 & 1.22 \\
\hline
\end{tabular}

${ }^{a}$ Not measured; ${ }^{b}$ significant interference from matrix, Hexa and Pentas not detected, but insignificant contribution from these to the Dioxin Equivalent TEF assumptions; ${ }^{\mathrm{c}}$ indicative;

${ }^{\mathrm{d}}$ WHO2005-TEQ calculated assuming the same toxicity TEF values for Dioxin TEQ; CLO, compost-like-output; MBMA, meat and bone meal ash; PLA, poultry litter ash; PSA, paper sludge ash; RWW, recycled waste wood. 
The $\mathrm{WHO}_{2005}$-TEQ contribution from $\mathrm{PBDD} / \mathrm{Fs}$ in the biosolids samples measured here was 4-7 times greater than the $\mathrm{WHO}_{2005}$-TEQ for PCDD/Fs (10.5-12.4 $\mathrm{ng} \mathrm{kg}^{-1} \mathrm{DS}$, Table 4) and was consistent with Venkatesan and Haldan [42], who also found a significantly greater $\mathrm{WHO}_{2005}$-TEQ contribution from $\mathrm{PBDD} / \mathrm{Fs}$ than their chlorinated analogs. The CLOs had lower $\mathrm{WHO}_{2005}-\mathrm{TEQ}$ values for PBDD/Fs than the biosolids equivalent to $18.0-32.2 \mathrm{ng} \mathrm{kg}^{-1} \mathrm{DS}$ (Table 9). PBDD/Fs and PBBs may be present as impurities in commercial brominated flame retardants [42] which explains their presence in municipal biosolids and CLO derived from MSW. Fewer PBDD/Fs congeners (11) were analysed compared to the $\mathrm{PCDD} / \mathrm{Fs}$ (17 PCDD/F congeners were determined) due to the more restricted availability analytical standardsfor PBDD/Fs, hence the missing congeners could also contribute to the overall TEQ, further increasing the potential significance of $\mathrm{PBDD} / \mathrm{Fs}$ in comparison to $\mathrm{PCDD} / \mathrm{Fs}$.

The concentrations of PBDD/Fs in the other materials were significantly smaller compared to the biosolids and CLOs, with upper bound $\mathrm{WHO}_{2005}$-TEQ values generally $<1 \mathrm{ng} \mathrm{kg}^{-1} \mathrm{DS}$, with the exception of PLA2 and RWW1, which had $\mathrm{WHO}_{2005}$-TEQ values of 5.11 and $3.05 \mathrm{ng} \mathrm{kg}^{-1} \mathrm{DS}$, respectively (Table 9). A potentially significant mechanism of PBDD/F formation is during the combustion of products containing polybrominated diphenylethers (PBDEs), which are used extensively as flame retardant chemicals [42]. However, the small concentrations of PBDD/Fs detected in most of the ash materials collected for this investigation were expected because they generally consisted of feedstocks that were unlikely to contain PBDEs. For example, PSA is produced from the combustion of paper manufacturing sludge and PLA2 was supplied from a straw-burning plant and poultry litter biomass power plant (Table 1).

The congener present in by far the greatest concentration was 1,2,3,4,6,7,8-HeptaBDF, with values measured in biosolids and CLO in the range: $716-4150 \mathrm{ng} \mathrm{kg}^{-1} \mathrm{DS}$. For example, this congener represented $94 \%$ of the total mass of the BDD/BDF congeners measured in biosolids samples, consistent with Venkatesan and Halden [42]. Additionally, 1,2,3,4,7,8-HexaBDF was also a relatively dominant congener with concentrations ranging from $53.2 \mathrm{ng} \mathrm{kg}^{-1}$ DS in CLO1 to $132 \mathrm{ng} \mathrm{kg}^{-1}$ DS in Biosolids2.

The greatest $\mathrm{WHO}_{2005}$-TEQ values for non-ortho PBBs were recorded for the CLOs with upper bound values of $0.04 \mathrm{ng} \mathrm{kg}^{-1}$ (Table 10). The $\mathrm{WHO}_{2005}$-TEQ values for the biosolids were lower at $0.02 \mathrm{ng} \mathrm{kg}^{-1}$ DS. The other materials had $\mathrm{WHO}_{2005}$-TEQ values of $0.003-0.01 \mathrm{ng} \mathrm{kg}^{-1} \mathrm{DS}$. These concentrations were smaller than those measured for the chlorinated analogs (Table 7). Overall, the contributions of PBDD/Fs and dioxin like PBBs to the $\mathrm{WHO}_{2005}$-TEQ values for biosolids, were equivalent to $40.3-77.9 \mathrm{ng} \mathrm{kg}^{-1} \mathrm{DS}$ compared to $11.5-14.0 \mathrm{ng} \mathrm{kg}^{-1}$ DS for PCDD/Fs and PCBs. Thus, risk assessments that only consider PCDD/Fs and PCBs may underestimate the potential total toxicity of dioxin-like compounds present in environmental media.

Ortho-PBBs concentrations in the waste samples were generally below the detection limit (Table 11). However, certain congeners, for example, BB-15 and BB-153 were detected in the biosolids and RWW at concentrations between $0.002-0.04 \mu \mathrm{g} \mathrm{kg}{ }^{-1} \mathrm{DS}$. The concentrations of ortho-PBBs were significantly smaller than those of ortho-PCBs (Table 8). In comparison to their chlorinated counterparts, there has been little research to date on the presence of PBDDs, PBDFs and PBBs in biosolids, other wastes and in the environment. Hence, these data represent some of the first to be reported on PBDD/Fs concentrations in waste samples from the UK and internationally. 
Table 10. Non-ortho polybrominated biphenyl (PBB) concentrations in waste samples (DS basis).

\begin{tabular}{|c|c|c|c|c|c|c|c|c|c|c|c|c|c|}
\hline & \multicolumn{2}{|c|}{ Biosolids } & \multicolumn{2}{|c|}{ CLO } & \multicolumn{2}{|c|}{ МВМА } & \multicolumn{2}{|c|}{ PLA } & \multirow[t]{2}{*}{ PSA } & \multicolumn{4}{|c|}{ RWW } \\
\hline & 1 & 2 & 1 & 2 & 1 & 2 & 1 & 2 & & 1 & 2 & 3 & 4 \\
\hline & \multicolumn{13}{|c|}{$\mathrm{ng} \mathrm{kg}^{-1} \mathrm{DS}$} \\
\hline PBB-77 & 0.31 & 0.45 & 0.33 & 0.49 & 0.13 & 0.12 & $<0.04$ & 0.18 & $<0.04$ & $0.04^{\mathrm{a}}$ & $<0.05$ & $<0.05$ & 0.06 \\
\hline PBB-126 & 0.20 & 0.13 & 0.35 & 0.37 & $<0.08$ & $<0.08$ & $<0.03$ & $<0.08$ & $<0.02$ & $<0.04$ & $<0.05$ & $<0.04$ & $<0.09$ \\
\hline PBB-169 & 0.17 & 0.58 & 0.66 & 0.17 & $<0.08$ & $<0.09$ & $<0.04$ & $<0.08$ & $<0.03$ & $<0.04$ & $<0.05$ & $<0.04$ & $<0.23$ \\
\hline TEQ $^{\mathrm{b}}$ lower & 0.02 & 0.02 & 0.04 & 0.04 & $<0.01$ & $<0.01$ & $<0.01$ & $<0.01$ & $<0.01$ & $<0.01$ & $<0.01$ & $<0.01$ & $<0.01$ \\
\hline TEQ ${ }^{\mathrm{b}}$ upper & 0.02 & 0.02 & 0.04 & 0.04 & 0.01 & 0.01 & 0.003 & 0.01 & 0.003 & 0.004 & 0.01 & 0.01 & 0.01 \\
\hline Sum & 0.69 & 1.16 & 1.33 & 1.03 & 0.28 & 0.28 & 0.11 & 0.34 & 0.09 & 0.12 & 0.14 & 0.13 & 0.38 \\
\hline
\end{tabular}

${ }^{\mathrm{a}}$ Indicative due to analyte suppression on instrument; ${ }^{\mathrm{b}} \mathrm{WHO}_{2005}$-TEQ calculated assuming the same toxicity TEF values for PCB TEQ; CLO, compost-like-output; MBMA, meat and bone meal ash; PLA, poultry litter ash; PSA, paper sludge ash; RWW, recycled waste wood.

Table 11. Ortho-polybrominated biphenyl (PBB) concentrations in waste samples (DS basis).

\begin{tabular}{|c|c|c|c|c|c|c|c|c|c|c|c|c|c|}
\hline & \multicolumn{2}{|c|}{ Biosolids } & \multicolumn{2}{|c|}{ CLO } & \multicolumn{2}{|c|}{ МВМА } & \multicolumn{2}{|c|}{ PLA } & \multirow[t]{2}{*}{ PSA } & \multicolumn{4}{|c|}{ RWW } \\
\hline & 1 & 2 & 1 & 2 & 1 & 2 & 1 & 2 & & 1 & 2 & 3 & 4 \\
\hline & \multicolumn{13}{|c|}{$\mu \mathrm{g} \mathrm{kg}{ }^{-1} \mathrm{DS}$} \\
\hline BB-15 & 0.003 & 0.02 & 0.01 & 0.02 & $<0.002$ & $<0.002$ & $<0.002$ & $<0.002$ & $<0.002$ & 0.03 & 0.004 & $<0.002$ & $<0.003$ \\
\hline BB-49 & $<0.002$ & $<0.002$ & $<0.003$ & $<0.003$ & $<0.002$ & $<0.002$ & $<0.002$ & $<0.002$ & $<0.002$ & $<0.002$ & $<0.002$ & $<0.002$ & $<0.003$ \\
\hline BB-52 & $<0.002$ & $<0.002$ & $<0.003$ & $<0.003$ & $<0.002$ & $<0.002$ & $<0.002$ & $<0.002$ & $<0.002$ & $<0.002$ & $<0.002$ & $<0.002$ & $<0.003$ \\
\hline BB-80 & $<0.002$ & $<0.003$ & $<0.003$ & $<0.014$ & $<0.002$ & $<0.002$ & $<0.002$ & $<0.002$ & $<0.002$ & $<0.002$ & $<0.002$ & $<0.002$ & $<0.003$ \\
\hline BB-101 & $<0.002$ & $<0.002$ & $<0.003$ & $<0.003$ & $<0.002$ & $<0.002$ & $<0.002$ & $<0.002$ & $<0.002$ & $<0.002$ & $<0.002$ & $<0.002$ & $<0.003$ \\
\hline BB-153 & 0.04 & 0.03 & 0.09 & 0.32 & $<0.002$ & $<0.002$ & $<0.002$ & $<0.002$ & $<0.002$ & 0.004 & 0.002 & $<0.002$ & $<0.003$ \\
\hline Sum & 0.05 & 0.06 & 0.11 & 0.36 & 0.01 & 0.01 & 0.01 & 0.01 & 0.01 & 0.04 & 0.01 & 0.01 & 0.02 \\
\hline
\end{tabular}

CLO, compost-like-output; MBMA, meat and bone meal ash; PLA, poultry litter ash; PSA, paper sludge ash; RWW, recycled waste wood. 


\subsection{Mixed Halogenated Dibenzo-p-Dioxin (PXDD), Dibenzofuran (PXDF) and Mixed Halogenated} Biphenyl (PXB) Concentrations

The concentrations of PXDD/Fs and PXBs in waste samples are presented in Tables 12 and 13. For several of the waste materials, including PLA1, PSA, RWW3 and RWW4 most or all of the individual congeners were below detection limits. However, for the biosolids, CLOs, MBMAs, PLA2 and RWW 1 and 2 , between $7-11$ of the congeners were detected. The congeners found in the greatest concentrations were 2-Br-3,6,7,8,9-ClDx, which was present at $1.07 \mathrm{ng} \mathrm{kg}^{-1} \mathrm{DS}$ in PLA2, and 2-Br-7,8-CIDf was at concentrations of up to $1.36 \mathrm{ng} \mathrm{kg}^{-1}$ DS in Biosolids2. The total sum of PXDD/Fs that could be quantified is significantly lower than for PCDD/Fs or PBDD/Fs (Tables 4 and 9). However, the compounds measured here are a small sub-set of the potentially large number of laterally substituted (and hence, potentially toxic) mixed halogenated congeners. Theoretically, there are 337 possible PXDDs and 647 possible PXDFs with bromo- or chloro- substitutions in the 2,3,7,8 positions, including 13 tetra-substituted and 90 penta-substituted congeners [43]. Thus, there are numerous possible combinations of mixed halogenated dioxins and biphenyls that correspond to each laterally substituted PCDD/F or PCB congener, and it was only possible to analyse one or two of each combination with currently available analytical standards. For example, the polychlorinated 1,2,3,7,8,-PeCDF exists as a single congener, but there are 30 possible mixed halogenated analogues and only two of these have been analysed (1Br2,3,7,8,ClDF and $1,3 \mathrm{Br} 2,7,8 \mathrm{ClDF})$. Practically, the limited range of primary and ${ }^{13} \mathrm{C}$ labelled analytical standards that are currently available for PXDD/F analysis hinders the reliable measurement of a larger selection of mixed halogenated compounds. The $\mathrm{WHO}_{2005}$-TEQ values for mixed halogenated dioxins and biphenyls could not been calculated because the dataset of congeners was not sufficiently comprehensive, and additionally quantitative data are lacking to define robust toxic equivalence factors (TEFs) for the PXDDs and PXDFs. Nevertheless, the contribution of these diverse groups of compounds to the overall $\mathrm{WHO}_{2005}$-TEQ could be significant considering the many possible mixed halogenated congeners potentially present in the environment.

\subsection{Polycyclic Aromatic Hydrocarbon (PAH) Concentrations}

The results for from an initial assessment of 4 significant PAH congeners [44] in the waste samples are presented in Table 14. The values indicated that the greatest concentrations of PAHs were present in the biosolids, CLOs and RWWs (with the exception of RWW3). Of the two biosolids samples, Biosolids2 had the greater $\sum$ PAH4 value, equivalent to $719 \mu \mathrm{g} \mathrm{kg}^{-1} \mathrm{DS}$ compared to $414 \mu \mathrm{g} \mathrm{kg}^{-1} \mathrm{DS}$ for Biosolids1. The CLO2 sample had a larger $\sum$ PAH4 content compared to CLO1 of $563 \mu \mathrm{g} \mathrm{kg}^{-1}$ DS compared to $336 \mu \mathrm{g} \mathrm{kg}^{-1} \mathrm{DS}$, respectively (Table 14). The Grade C RWW2 had the largest $\sum$ PAH4 value of $390 \mu \mathrm{g} \mathrm{kg}^{-1}$ DS, compared to RWW1 and RWW3, which contained 342 and $285 \mu \mathrm{g} \mathrm{kg}^{-1} \mathrm{DS}$, respectively. The concentrations of PAHs in the two biosolids samples were lower than those reported by Jones et al. [45] for primary and secondary sludge from UK wastewater treatment plants. For example, for Biosolids1 and Biosolids2, the concentrations of benzo[a]pyrene and benzo[b] fluoranthene were 157 and $176 \mu \mathrm{g} \mathrm{kg}^{-1} \mathrm{DS}$ and 169 and $302 \mu \mathrm{g} \mathrm{kg}^{-1} \mathrm{DS}$, respectively, whereas Jones et al. [45] reported median concentrations of $320 \mu \mathrm{g} \mathrm{kg}^{-1}$ and $310 \mu \mathrm{g} \mathrm{kg}^{-1}$, respectively, for these PAH congeners in sludge. The biosolids isampled here had undergone anaerobic digestion whereas the primary and secondary sludges 
investigated by Jones et al. [45] were untreated. However, it is unlikely that the lower concentrations observed for Biosolids1 and 2 were due to removal during anaerobic digestion, as PAHs are relatively recalcitrant, and modest removals of only approximately $10 \%$ have been observed for benzo[a]pyrene and benzo[b]fluoranthene under normal mesophilic digestion conditions [46]. Indeed, VS destruction during sewage sludge treatment processes, such as anaerobic digestion, may increase the concentration of conservative contaminants in the treated residual sludge [47]. The concentrations of $\sum$ PAH4 in biosolids, CLO, and RWW1 and 2 were similar to or greater than the median value measured for rural soil in the UK of $296 \mu \mathrm{g} \mathrm{kg}^{-1}$ ds (Table 5). However, the concentrations measured in waste samples were smaller than the median content in UK urban soil of $1430 \mu \mathrm{g} \mathrm{kg}^{-1} \mathrm{DS}$.

The concentrations of PAHs measured in the biosolids and CLO samples were significantly smaller than the limits existing or proposed for PAHs in biosolids and composts, however, it is important to note the values in the standards are for greater numbers of PAH congeners (Table 6). The PAH concentrations in the ash samples were significantly smaller compared to the other waste types examined. The largest $\sum$ PAH4 concentration measured in ash was detected in PLA2, at $97 \mu \mathrm{g} \mathrm{kg}^{-1} \mathrm{DS}$, compared to values in the range of $0-17 \mu \mathrm{g} \mathrm{kg}^{-1} \mathrm{DS}$ for the other ash types tested. The small concentrations of PAHs in the waste materials are consistent with the declining burden of these compounds in the UK environment [5].

\subsection{Polybrominated Diphenyl Ether (PBDE) and Deca-Brominated Diphenyl Ether} (BDE)/Brominated Biphenyl (BB)

The concentrations of PBDEs in the waste samples are presented in Table 15. Biosolids contained more PBDEs compared to the other waste materials tested, equivalent to $90.5-103 \mu \mathrm{g} \mathrm{kg}^{-1} \sum$ PBDEs DS. Knoth et al. [48] reported the median PBDE concentration for sewage sludge from 11 wastewater treatment plants, based on the sum of 6 significant congeners (28, 47, 99, 153, 154 and 183), was $108 \mu \mathrm{g} \mathrm{kg}^{-1} \mathrm{DS}$. For the same 6 congeners, the concentration in the biosolids samples measured here was slightly less and in the range 77-88 $\mu \mathrm{g} \mathrm{kg}^{-1}$ DS. Jones et al. [45] reported median concentrations of 21, 33, 6, 5 and $5 \mu \mathrm{g} \mathrm{kg}^{-1}$ for BDEs 47, 99, 100, 153 and 154 in sludge from UK wastewater treatment plants; these median values were very similar to the corresponding PBDE concentrations detected in the biosolids samples examined here. The CLOs also contained relatively high concentrations of PBDEs with total concentrations equivalent to $40.5-59.5 \mu \mathrm{g} \mathrm{kg}^{-1} \mathrm{DS}$.

The $\sum$ PBDE in the other waste types were relatively smaller and in the range $0.52-4.34 \mu \mathrm{g} \mathrm{kg}^{-1} \mathrm{DS}$. PBDEs are destroyed during waste combustion treatment processes, therefore the small concentrations detected in the ash samples were as expected [49]. 
Table 12. Mixed halogenated dibenzo- $p$-diozin (PXDD) and dibenzofuran (PXDF) concentrations in waste samples (DS basis).

\begin{tabular}{|c|c|c|c|c|c|c|c|c|c|c|c|c|c|}
\hline & \multicolumn{2}{|c|}{ Biosolids } & \multicolumn{2}{|c|}{ CLO } & \multicolumn{2}{|c|}{ МВMA } & \multicolumn{2}{|c|}{ PLA } & \multirow[t]{2}{*}{ PSA } & \multicolumn{4}{|c|}{ RWW } \\
\hline & 1 & 2 & 1 & 2 & 1 & 2 & 1 & 2 & & 1 & 2 & 3 & 4 \\
\hline & \multicolumn{13}{|c|}{$\mathrm{ng} \mathrm{kg}^{-1} \mathrm{DS}$} \\
\hline 2Br78ClDf & 0.56 & 1.36 & 1.28 & 0.74 & 0.12 & 0.23 & $<0.02$ & 0.49 & $<0.08$ & 0.34 & 0.19 & $<0.03$ & 0.05 \\
\hline 2Br78ClDx & 0.98 & 0.43 & 0.14 & 0.17 & 0.04 & 0.14 & $<0.02$ & 0.27 & $<0.08$ & 0.05 & 0.03 & $<0.03$ & $<0.02$ \\
\hline 2Br378ClDx & 0.03 & 0.04 & 0.035 & $<0.02$ & $<0.03$ & 0.05 & $<0.01$ & 0.13 & $<0.06$ & 0.05 & 0.05 & $<0.02$ & 0.02 \\
\hline 23Br78ClDx & $<0.02$ & $<0.02$ & $<0.03$ & $<0.03$ & $<0.02$ & $<0.01$ & $<0.01$ & 0.02 & $<0.04$ & 0.02 & $<0.01$ & $<0.01$ & $<0.01$ \\
\hline 1Br2378ClDx & $<0.02$ & $<0.02$ & $<0.03$ & $<0.03$ & $<0.03$ & 0.04 & $<0.01$ & 0.06 & $<0.06$ & $<0.03$ & 0.05 & $<0.02$ & $<0.02$ \\
\hline 2Br1378ClDx & $<0.02$ & $<0.02$ & $<0.01$ & $<0.01$ & $<0.02$ & 0.10 & $<0.01$ & $0.18 i$ & $<0.04$ & $<0.02$ & $<0.01$ & $<0.01$ & $<0.01$ \\
\hline 2Br36789ClDx & 0.05 & 0.21 & 0.04 & 0.11 & 0.16 & 0.38 & $<0.02$ & 1.07 & $<0.10$ & $<0.05$ & 0.11 & $<0.03$ & 0.03 \\
\hline 3Br278ClDf & 0.04 & 0.16 & 0.16 & 0.08 & 0.05 & 0.05 & $<0.01$ & 0.21 & $<0.06$ & 0.05 & $<0.02$ & $<0.02$ & 0.02 \\
\hline 2Br678ClDf & 0.12 & 0.18 & 0.18 & 0.12 & 0.07 & 0.09 & 0.01 & 0.20 & $<0.03$ & 0.04 & $<0.01$ & $<0.01$ & $<0.01$ \\
\hline 23Br78ClDf & 0.06 & 0.13 & 0.14 & 0.12 & 0.03 & $<0.01$ & $<0.01$ & 0.02 & $<0.03$ & $<0.01$ & 0.08 & 0.02 & 0.02 \\
\hline 1Br2378ClDf & $<0.02$ & $<0.02$ & 0.03 & 0.05 & $<0.02$ & $<0.01$ & $<0.01$ & $<0.09$ & $<0.04$ & $<0.02$ & $<0.01$ & $<0.01$ & $<0.01$ \\
\hline 4Br2378ClDf & 0.09 & 0.15 & 0.30 & 0.14 & 0.26 & 0.08 & $<0.02$ & 0.26 & $<0.09$ & $0.08^{\mathrm{a}}$ & $0.05^{\mathrm{a}}$ & 0.05 & $<0.02$ \\
\hline 13Br278ClDf & $<0.02$ & $<0.02$ & 0.03 & $<0.02$ & $<0.01$ & 0.01 & $<0.01$ & 0.02 & $<0.02$ & $<0.01$ & $<0.01$ & $<0.01$ & $<0.01$ \\
\hline Sum & 2.04 & 2.77 & 2.40 & 1.63 & 0.88 & 1.19 & 0.17 & 3.00 & 0.73 & 0.76 & 0.64 & 0.28 & 0.25 \\
\hline
\end{tabular}

a Indicative due to analyte suppression on instrument; CLO, compost-like-output; MBMA, meat and bone meal ash; PLA, poultry litter ash; PSA, paper sludge ash; RWW, recycled waste wood. 
Table 13. Mixed halogenated biphenyl (NXB) concentrations in waste samples (DS basis).

\begin{tabular}{|c|c|c|c|c|c|c|c|c|c|c|c|c|c|}
\hline & \multicolumn{2}{|c|}{ Biosolids } & \multicolumn{2}{|c|}{ CLO } & \multicolumn{2}{|c|}{ МВМА } & \multicolumn{2}{|c|}{ PLA } & \multirow[t]{2}{*}{ PSA } & \multicolumn{4}{|c|}{ RWW } \\
\hline & 1 & 2 & 1 & 2 & 1 & 2 & 1 & 2 & & 1 & 2 & 3 & 4 \\
\hline & \multicolumn{13}{|c|}{$\mathrm{ng} \mathrm{kg}^{-1} \mathrm{DS}$} \\
\hline 4'Br33'45Cl PXB 126 & 0.04 & 0.04 & 0.03 & 0.05 & $<0.06$ & $<0.03$ & $<0.03$ & 0.03 & $<0.12$ & $<0.05$ & 0.05 & $<0.04$ & $<0.03$ \\
\hline 34Br3'4'5'Cl PXB 126 di-Br & $<0.02$ & $<0.02$ & 0.04 & 0.04 & $<0.01$ & $<0.01$ & 0.01 & $<0.01$ & $<0.03$ & 0.02 & $<0.01$ & $<0.01$ & $<0.01$ \\
\hline 3'4'5'Br34Cl PXB 126 tri- $\mathrm{Br}$ & $<0.02$ & $<0.02$ & $<0.01$ & $<0.01$ & $<0.03$ & $<0.01$ & $<0.01$ & $<0.01$ & $<0.06$ & $<0.03$ & $<0.02$ & $<0.02$ & $<0.02$ \\
\hline Sum & 0.08 & 0.09 & 0.07 & 0.09 & 0.11 & 0.05 & 0.05 & 0.05 & 0.20 & 0.10 & 0.07 & 0.07 & 0.05 \\
\hline
\end{tabular}

CLO, compost-like-output; MBMA, meat and bone meal ash; PLA, poultry litter ash; PSA, paper sludge ash; RWW, recycled waste wood.

Table 14. Preliminary polycyclic aromatic hydrocarbon (PAH) concentrations in waste samples (DS basis)

\begin{tabular}{|c|c|c|c|c|c|c|c|c|c|c|c|c|c|}
\hline & \multicolumn{2}{|c|}{ Biosolids } & \multicolumn{2}{|c|}{ CLO } & \multicolumn{2}{|c|}{ MBMA } & \multicolumn{2}{|c|}{ PLA } & \multirow[t]{2}{*}{ PSA } & \multicolumn{4}{|c|}{ RWW } \\
\hline & 1 & 2 & 1 & 2 & 1 & 2 & 1 & 2 & & 1 & 2 & 3 & 4 \\
\hline & \multicolumn{13}{|c|}{$\mu \mathrm{g} \mathrm{kg}^{-1} \mathrm{DS}$} \\
\hline benz (a) anthracene & 19 & 87 & 23 & 22 & 0 & 5 & 4 & 21 & $<0.07$ & 26 & 30 & 170 & 78.9 \\
\hline chrysene & 69 & 153 & 116 & 97 & 0 & 8 & 5 & 27 & $<0.08$ & 129 & 125 & 59 & 76.4 \\
\hline benzo[b]fluoranthene & 169 & 302 & 107 & 270 & 0 & 4 & 5 & 25 & $<0.08$ & 93 & 114 & 32 & 45.2 \\
\hline benzo[a]pyrene & 157 & 176 & 90 & 174 & 0 & 6 & 4 & 23 & $<0.09$ & 95 & 121 & 23 & 34.2 \\
\hline PAH 4 Sum Lower & 414 & 719 & 336 & 563 & 1 & 23 & 17 & 97 & $<0.07$ & 342 & 390 & 285 & 235 \\
\hline PAH 4 Sum Upper & 414 & 719 & 336 & 563 & 1 & 23 & 17 & 97 & 0 & 342 & 390 & 285 & 235 \\
\hline
\end{tabular}

Values reported to rounded figures are estimates only; CLO, compost-like-output; MBMA, meat and bone meal ash; PLA, poultry litter ash; PSA, paper sludge ash; RWW, recycled waste wood. 
The PBDE congeners present in the greatest concentrations were BDE-47 and BDE-99. The concentrations of BDE-47 in biosolids and CLO were in the ranges $25.4-32.9 \mu \mathrm{g} \mathrm{kg} \mathrm{gg}^{-1}$ and 10.4-12.9 $\mathrm{g} \mathrm{kg} \mathrm{kg}^{-1} \mathrm{DS}$, respectively. The concentration of BDE-99 in the biosolids samples was $25.0-42.0 \mu \mathrm{g} \mathrm{kg}^{-1}$ DS and was $11.9-15.1 \mu \mathrm{g} \mathrm{kg}^{-1}$ DS in CLO. The BDE-99 congener is one of the main constituents of commercial penta-BDE formulations, which may explain its relatively high abundance [5]. In addition, BDE-49, BDE-66, BDE-100, BDE-153, BDE-154 and BDE-183 were generally present in the biosolids and CLOs at concentrations between $1-10 \mu \mathrm{g} \mathrm{kg}^{-1} \mathrm{DS}$, whereas the remaining PBDE congeners were $<1 \mu \mathrm{g} \mathrm{kg}^{-1} \mathrm{DS}$. The biosolids samples contained the largest amounts of deca-BDE, followed by CLO and RWW (Table 16). Biosolids2 contained an indicative concentration of $6690 \mu \mathrm{g} \mathrm{kg}^{-1}$ DS compared to $4200 \mu \mathrm{g} \mathrm{kg}^{-1}$ DS in Biosolids1. The deca-BDE-209 content in the biosolids samples was greater than the concentrations measured by Knoth et al. [48] in sewage sludge sampled from 11 municipal wastewater treatment plants in Germany, which contained a median value of $108 \mu \mathrm{g} \mathrm{kg}^{-1}$ (range 12.5-288 $\mu \mathrm{g} \mathrm{kg}^{-1} \mathrm{DS}$ ). Both CLO samples had similar concentrations of deca-BDE in the range 1650-1720 $\mu \mathrm{g} \mathrm{kg}^{-1}$ DS and the RWW1 and RWW2 samples also contained appreciable amounts of deca-BDE in the range $143-246 \mu \mathrm{g} \mathrm{kg}^{-1} \mathrm{DS}$, reflecting the use of deca-BDEs as flame-retardants including in furniture manufacturing. The relatively high concentrations of deca-BDE-209, in comparison to the penta- and octa-BDEs (Table 15), potentially reflects the expanding use of deca-BDEs as flame retardant chemicals in Europe, since the prohibition of preparations containing penta and octa-BDE by the European Union in 2003 [50]. However, in 2012, deca-BDE was listed by the European Chemicals Agency (ECHA) as a substance of very high concern, and has since been proposed for listing under the Stockholm Convention for Persistent Organic Pollutants (POPs) [51]; its status as a POP is currently under review.

The concentrations of deca-BDE in the other RWWs, the PLAs, and the MBMAs were small and between $0.62 \mu \mathrm{g} \mathrm{kg}^{-1}$ DS for MBMA2 to $11.0 \mu \mathrm{g} \mathrm{kg}^{-1}$ DS for RWW4. The deca-BB-209 concentrations were also significantly smaller overall in the different waste types tested compared to deca-BDE and ranged between $0.01 \mu \mathrm{g} \mathrm{kg}^{-1}$ DS for RWW2 and 3, to 0.48 for CLO1. Again, low concentrations of deca-BDEs were anticipated for the ash materials as they are destroyed during waste incineration [49].

\subsection{Hexabromocyclododecanes (HBCDs), Pentabromocyclododecene (PBCD) and}

\section{Tetrabromobisphenol A (TBBPA) Concentrations}

Results of the analysis for the brominated flame-retardants: HBCD, PBCD, TBBPA, are presented in Table 17. The largest concentrations of HBCDs were found in the CLOs, biosolids and RWW1 and were broadly in similar ranges in these materials. For example, biosolids samples contained the largest amounts of $\gamma$-HBCD in the range $302-392 \mu \mathrm{g} \mathrm{kg}^{-1} \mathrm{DS}$.

TBBPA was the next most significant compound detected of this group of brominated flame-retardants and the biosolids samples contained similar amounts of TBBPA in the range $33-45 \mu \mathrm{g} \mathrm{kg}^{-1}$ DS. $\gamma$-HBCD was present in the greatest concentrations in CLO2, between 139-836 $\mathrm{g} \mathrm{kg}^{-1} \mathrm{DS}$, and TBBPA was present in the greatest concentrations in CLO1, between $493-517 \mu \mathrm{g} \mathrm{kg}^{-1} \mathrm{DS}$. $\alpha$-HBCD was also present in the largest amounts in CLO at 121-302 $\mu \mathrm{g} \mathrm{kg}^{-1}$ DS for CLO2 and 26-70 $\mu \mathrm{g} \mathrm{kg}^{-1}$ DS for CLO1, and CLO2 also contained the most $\beta$-HBCD, equivalent to $34-78 \mu \mathrm{g} \mathrm{kg}^{-1} \mathrm{DS}$, compared to the other waste sample types examined. PBCD was also elevated in CLO compared to the other waste materials tested; overall, the largest concentration of PBCD was measured in CLO2, between $42-351 \mu \mathrm{g} \mathrm{kg}^{-1} \mathrm{DS}$, and 
CLO1 contained a smaller amount between 13-29 $\mathrm{g} \mathrm{kg}^{-1} \mathrm{DS}$. The largest concentrations of this group of brominated flame-retardants measured in RWW were generally detected in RWW1, which contained $67-169 \mu \mathrm{g} \mathrm{kg}^{-1}$ DS of $\gamma-\mathrm{HBCD}$ and $19-45 \mu \mathrm{g} \mathrm{kg}^{-1}$ DS of $\alpha$-HBCD. The results also indicated that these compounds were detected at elevated amounts in RWW2, but the concentrations were generally smaller compared to RWW1, for instance the $\gamma$-HBCD content in RWW2 was equivalent to $21.2 \mu \mathrm{g} \mathrm{kg}^{-1} \mathrm{DS}$. However, RWW2 potentially contained the largest overall amount of TBBPA detected in the RWW samples examined with an indicative concentration of $52 \mu \mathrm{g} \mathrm{kg}^{-1} \mathrm{DS}$. HBCDs, PBCD and TBBPA were also detected in waste wood samples RWW3 and 4, although concentrations were generally very small and typically $\leq 1 \mu \mathrm{g} \mathrm{kg}^{-1} \mathrm{DS}$. The relatively large concentrations of these flame-retardants in CLO, which originates from the organic fraction of MSW, biosolids and, in some cases, in RWW may be expected because they are found in many materials in the domestic environment including fabrics, packaging materials and plastics [5].

Concentrations of these brominated flame-retardants were generally below detection limits in the ash materials. However, TBBPA was detected in PLA1 at $42 \mu \mathrm{g} \mathrm{kg}^{-1} \mathrm{DS}$, and $\alpha$ - and $\beta$-HBCD were also detected, although at very low concentrations $\leq 0.12 \mu \mathrm{g} \mathrm{kg}^{-1} \mathrm{DS}$. These two stereoisomers, plus $\gamma$-HBCD were also detected at very low concentrations in MBMA2, at $\leq 0.18 \mu \mathrm{g} \mathrm{kg}{ }^{-1} \mathrm{DS}$. The results from the analysis of waste ash materials were therefore consistent with the near complete destruction of HBCDs observed by MSW incineration [52].

\subsection{Polychlorinated Napthalene (PCN) Concentrations}

The PCN data are presented in Table 18 and showed the largest amounts of this compound group were found in the biosolids, CLO and RWW1 samples. CLO1 had the largest overall $\sum$ PCN concentration of $1980 \mathrm{ng} \mathrm{kg}^{-1} \mathrm{DS}$, compared to $680 \mathrm{ng} \mathrm{kg}^{-1}$ DS for CLO2. Biosolids1 contained a similar $\sum \mathrm{PCN}$ compared to CLO2, equivalent to $743 \mathrm{ng} \mathrm{kg}^{-1} \mathrm{DS}$, and Biosolids2 contained $541 \mathrm{ng} \mathrm{kg}^{-1} \mathrm{DS}$ of $\sum \mathrm{PCN}$. The $\sum \mathrm{PCN}$ values detected here are therefore significantly smaller than mean $\sum \mathrm{PCN}$ concentrations in sewage sludge reported by Smith [7] and Clarke and Smith [53] of 83,000 $\mathrm{ng} \mathrm{kg}^{-1}$ DS (range 5000-190,000 $\mathrm{ng} \mathrm{kg}^{-1}$ DS) and 44,000 $\mathrm{ng} \mathrm{kg}^{-1} \mathrm{DS}$, respectively, and suggest that PCNs have further diminished as biosolids contaminants since these reviews of earlier surveys of sewage sludge chemical quality were reported.

Waste wood potentially contained more $\sum$ PCN than the biosolids and CLO samples. Thus, RWW1 contained $1210 \mathrm{ng} \mathrm{kg}^{-1}$ DS of $\sum$ PCN, followed by RWW2 with $604 \mathrm{ng} \mathrm{kg}^{-1} \mathrm{DS}$. Samples: RWW3 and 4 contained generally similar amounts of $\sum \mathrm{PCN}$, in the range $88.3-121 \mathrm{ng} \mathrm{kg}^{-1} \mathrm{DS}$ (as upper bound values). The range of maximum (upper bound) $\sum \mathrm{PCN}$ values measured in the ash materials examined were between $8.8 \mathrm{ng} \mathrm{kg}^{-1}$ DS in PLA1 to $108 \mathrm{ng} \mathrm{kg}^{-1}$ DS in MBMA2, respectively. The concentrations of PCNs in PSA were all below the limit of analytical detection.

The PCNs in greatest concentrations were PCN 52 and 53, present between 104-379 $\mathrm{ng} \mathrm{kg}^{-1} \mathrm{DS}$ and 195-737 $\mathrm{ng} \mathrm{kg}^{-1}$ DS, respectively, in the biosolids, CLOs, and RWW1 and 2 samples. CLO1 and RWW1 also contained PCN 69 in relatively larger concentrations compared to the other materials tested of 223 and $130 \mathrm{ng} \mathrm{kg}^{-1} \mathrm{DS}$, respectively, and PCN71/72 at 370 and $203 \mathrm{ng} \mathrm{kg}^{-1} \mathrm{DS}$, respectively. The remaining PCNs were generally present in the materials at concentrations $\leq 100 \mathrm{ng} \mathrm{kg}^{-1} \mathrm{DS}$.

PCNs have not been produced in the UK for over 35 years. Current potential sources are expected to be dominated by the disposal routes of capacitors and engine oil, where the majority of manufactured PCNs 
were used [5]. PCNs have also been found in fly ash and flue gas from waste incineration and landfills are also expected to be a source of PCN emissions [5]. However, the introduction of improved standards of waste incineration may increase the destruction of PCNs during combustion [54]. The low concentrations measured in the waste samples collected for this programme therefore reflect the declining emission and concentrations of PCNs in the environment.

\subsection{Screen for Perfluoroalkyl Substances (PFASs)}

An initial screen was conducted for the presence and abundance of PFASs in the waste materials (Table 19). PFASs were present in the greatest concentrations in the biosolids samples. Preliminary results indicated that concentrations of perfluorooctanoic acid (PFOA), perfluorononanoic acid (PFNA), perfluorodecanoic acid (PFDA) and perfluorooctane sulfonate (PFOS) were present in concentrations $>10 \mu \mathrm{g} \mathrm{kg}^{-1}$ DS in Biosolids1. The results indicated that PFDA and PFOS were also present in concentrations $>10 \mu \mathrm{g} \mathrm{kg}^{-1}$ DS in Biosolids2, and, in addition, perfluoroundecanoic acid (PFUnDA) was present in concentrations $>10 \mu \mathrm{g} \mathrm{kg}^{-1} \mathrm{DS}$ in this biosolids sample. The screen for PFASs in biosolids indicated that the concentrations of the majority of remaining PFASs investigated were between 1-10 $\mu \mathrm{g}$ $\mathrm{kg}^{-1}$ DS. Preliminary findings indicated that the concentration of PFASs were generally smaller than the ranges and mean values of PFOS and PFOA in biosolids reported by Clarke and Smith [53]; mean concentrations of these compounds estimated in that study were equivalent to $196 \mu \mathrm{g} \mathrm{kg}^{-1} \mathrm{DS}$ and $75 \mu \mathrm{g} \mathrm{kg}^{-1} \mathrm{DS}$, respectively. PFASs were also detected in concentrations $>1 \mu \mathrm{g} \mathrm{kg}^{-1} \mathrm{DS}$, but generally $<10 \mu \mathrm{g} \mathrm{kg}^{-1}$ DS in the CLOs and the RWWs, in particular RWW1. In addition, PFOA was found at concentrations $>10 \mu \mathrm{g} \mathrm{kg}^{-1}$ DS in CLO1, and RWW1. A targeted, quantitative chemical analysis will therefore be conducted to provide accurate concentration data for PFASs in the biosolids, CLO and RWW samples.

\subsection{Non-targeted Screen of New and Emerging Contaminants}

Several other groups of priority compounds were identified using a GC-ToF-MS screen approach and some key observations are summarised in Table 20.

The wastes were examined for a number of phthalate substances, nine of the samples contained one or more of dimethyl phthalate (DMP), diethyl phthalate (DEP), diisobutyl phthalate (DiBP), dibutyl phthalate (DBP), di(2-ethylhexyl)phthalate (DEHP), diisononyl phthalate (DiNP) and diisodecylphthalate (DiDP), up to an estimated maximum concentration of $32 \mathrm{mg} \mathrm{kg}^{-1}$ DS (in CLO2). The greatest concentrations were observed in the CLOs, followed by the biosolids samples. Concentrations of DEHP in biosolids ( $15 \mathrm{mg} \mathrm{kg}^{-1} \mathrm{DS}$ ) were generally similar to, albeit smaller than the mean literature value of $58 \mathrm{mg} \mathrm{kg}^{-1} \mathrm{DS}$ reported by Clarke and Smith [53]. The DEHP concentrations measured in the biosolids samples also corresponded to the mean and median values of 19 and $11 \mathrm{mg} \mathrm{kg}^{-1}$ for DEHP in sludge from UK wastewater treatment plants reported by Jones et al. [45].

The waste samples were examined for short (C10-C1) and medium (C14-C17) chain CPs. Medium chain CPs were detected in Biosolids2 and CLO1 at approximate concentrations of 9 and $3 \mathrm{mg} \mathrm{kg}^{-1} \mathrm{DS}$, respectively, but short chain CPs were not detected. Theconcentration in biosolids was significantly below the mean concentration of medium chain CPs of $910 \mathrm{mg} \mathrm{kg}^{-1} \mathrm{DS}$ reported by Clarke and Smith [53]. 
Table 15. Polybrominated diphenyl ether (PBDE) concentrations in waste samples (DS basis).

\begin{tabular}{|c|c|c|c|c|c|c|c|c|c|c|c|c|c|}
\hline & \multicolumn{2}{|c|}{ Biosolids } & \multicolumn{2}{|c|}{ CLO } & \multicolumn{2}{|c|}{ МВМА } & \multicolumn{2}{|c|}{ PLA } & \multirow[t]{2}{*}{ PSA } & \multicolumn{4}{|c|}{ RWW } \\
\hline & 1 & 2 & 1 & 2 & 1 & 2 & 1 & 2 & & 1 & 2 & 3 & 4 \\
\hline & \multicolumn{13}{|c|}{$\mu \mathrm{g} \mathrm{kg}^{-1} \mathrm{DS}$} \\
\hline $\mathrm{BDE}-17$ & 0.69 & 0.86 & 0.69 & 0.41 & 0.003 & 0.01 & 89.7 & 0.01 & $<0.01$ & 0.04 & 0.03 & $<0.002$ & 0.01 \\
\hline BDE-28/33 & 0.75 & 0.61 & 1.94 & 1.37 & 0.01 & 0.01 & $<0.01$ & 0.01 & $<0.01$ & 0.05 & 0.03 & 0.01 & 0.01 \\
\hline BDE-47 & 32.9 & 25.4 & 12.9 & 10.4 & 0.08 & 0.09 & $<0.01$ & 0.09 & 0.08 & 1.16 & 0.66 & 0.15 & 0.27 \\
\hline BDE-49 & 2.14 & 1.84 & 1.98 & 1.05 & 0.01 & 0.01 & 0.10 & 0.02 & 0.01 & 0.07 & 0.03 & 0.01 & 0.02 \\
\hline BDE-66 & 1.02 & 1.01 & 0.72 & 1.04 & 0.01 & 0.02 & 0.01 & 0.02 & $<0.01$ & 0.06 & 0.03 & 0.01 & 0.02 \\
\hline BDE-71 & 0.32 & 0.45 & 0.14 & 0.12 & $<0.002$ & $<0.002$ & 0.01 & $<0.002$ & $<0.002$ & 0.01 & $<0.002$ & $<0.002$ & $<0.003$ \\
\hline BDE-77 & 0.024 & 0.031 & 0.20 & 0.11 & $<0.002$ & $<0.002$ & $<0.002$ & $<0.002$ & $<0.002$ & 0.004 & $<0.002$ & $<0.002$ & $<0.003$ \\
\hline BDE-85 & 1.71 & 1.44 & 0.69 & 0.52 & 0.01 & 0.01 & $<0.002$ & 0.01 & $<0.01$ & 0.06 & 0.03 & 0.007 & 0.02 \\
\hline BDE-99 & 42.0 & 37.0 & 15.1 & 11.9 & 0.09 & 0.10 & $<0.006$ & 0.12 & $<0.07$ & 1.40 & 0.74 & 0.18 & 0.31 \\
\hline BDE-100 & 8.78 & 7.45 & 2.82 & 2.30 & 0.01 & 0.01 & 0.08 & 0.01 & $<0.01$ & 0.27 & 0.15 & 0.03 & 0.06 \\
\hline BDE-119 & 0.12 & 0.23 & 0.33 & 0.13 & $<0.002$ & $<0.002$ & 0.01 & 0.003 & $<0.002$ & 0.01 & 0.004 & $<0.002$ & $<0.003$ \\
\hline BDE-126 & $<0.02$ & $<0.01$ & $<0.02$ & $<0.01$ & $<0.002$ & 0.002 & $<0.002$ & $<0.002$ & $<0.002$ & $<0.002$ & $<0.002$ & $<0.002$ & $<0.003$ \\
\hline BDE-153 & 5.31 & 5.79 & 7.23 & 2.78 & 0.02 & 0.01 & $<0.002$ & 0.03 & $<0.01$ & 0.33 & 0.14 & 0.03 & 0.05 \\
\hline BDE-138 & 0.59 & 0.44 & 0.69 & 0.29 & 0.002 & $<0.002$ & 0.01 & 0.003 & $<0.002$ & 0.03 & 0.01 & $<0.002$ & $<0.003$ \\
\hline BDE-154 & 3.98 & 3.93 & 2.25 & 1.41 & 0.01 & $<0.007$ & $<0.002$ & 0.01 & 0.003 & 0.14 & 0.07 & 0.02 & 0.03 \\
\hline BDE-183 & 2.95 & 4.07 & 19.0 & 6.69 & 0.01 & 0.01 & 0.01 & 0.01 & $<0.002$ & 0.72 & 0.34 & 0.06 & 0.03 \\
\hline Sum & 103 & 90.5 & 59.5 & 40.5 & 0.26 & 0.28 & 0.22 & 0.33 & 0.09 & 4.34 & 2.26 & 0.52 & 0.82 \\
\hline Sum $6^{a}$ & 87.8 & 76.8 & 58.5 & 34.5 & 0.21 & 0.22 & 0.20 & 0.26 & 0.17 & 3.79 & 1.99 & 0.45 & 0.70 \\
\hline
\end{tabular}


Table 16. Deca-brominated diphenyl ether (BDE)/brominated biphenyl (BB) concentrations in waste samples (DS basis).

\begin{tabular}{|c|c|c|c|c|c|c|c|c|c|c|c|c|c|}
\hline & \multicolumn{2}{|c|}{ Biosolids } & \multicolumn{2}{|c|}{ CLO } & \multicolumn{2}{|c|}{ МВМА } & \multicolumn{2}{|c|}{ PLA } & \multirow[t]{2}{*}{ PSA } & \multicolumn{4}{|c|}{ RWW } \\
\hline & 1 & 2 & 1 & 2 & 1 & 2 & 1 & 2 & & 1 & 2 & 3 & 4 \\
\hline & \multicolumn{13}{|c|}{$\mu g \mathrm{~kg}^{-1} \mathrm{DS}$} \\
\hline BDE-209 & $4200^{\mathrm{a}}$ & $6690^{a}$ & $1720^{a}$ & $1650^{a}$ & 0.70 & 0.62 & $<0.17$ & 3.01 & $1.35 i$ & 246 & 143 & 7.94 & 11.0 \\
\hline BB-209 & 0.07 & 0.29 & 0.48 & 0.15 & 0.02 & 0.03 & $<0.24$ & 0.02 & $<0.22$ & 0.18 & 0.01 & 0.01 & 0.15 \\
\hline
\end{tabular}

${ }^{a}$ Indicative value, out of linear range; CLO, compost-like-output; MBMA, meat and bone meal ash; PLA, poultry litter ash; PSA, paper sludge ash; RWW, recycled waste wood.

Table 17. Hexabromocyclododecane (HBCD), pentabromocyclododecene and tetrabromobipshenol A (TBBPA) concentrations in the waste samples (DS basis).

\begin{tabular}{|c|c|c|c|c|c|c|c|c|c|c|c|c|c|}
\hline & \multicolumn{2}{|c|}{ Biosolids } & \multicolumn{2}{|c|}{ CLO } & \multicolumn{2}{|c|}{ МВМА } & \multicolumn{2}{|c|}{ PLA } & \multirow[t]{2}{*}{ PSA } & \multicolumn{4}{|c|}{$\mathbf{R W W}$} \\
\hline & 1 & 2 & 1 & 2 & 1 & 2 & 1 & 2 & & 1 & 2 & 3 & 4 \\
\hline \multicolumn{14}{|c|}{$\mu \mathrm{g} \mathrm{kg}{ }^{-1} \mathrm{DS}$} \\
\hline$\alpha-\mathrm{HBCD}$ & $8.3-19.7$ & 9.05 & $26-70$ & $121-302$ & $<0.01$ & $0.03^{\mathrm{a}}$ & 0.12 & $<0.01$ & $<0.01$ & $19-45$ & 9.35 & 0.76 & 1.06 \\
\hline ß-HBCD & $5.5-9.6$ & 6.37 & $3-7$ & $34-78$ & $<0.01$ & $0.01^{\mathrm{a}}$ & 0.03 & $<0.01$ & $<0.01$ & $10-20$ & 4.31 & 0.22 & 0.31 \\
\hline$\gamma-\mathrm{HBCD}$ & $302-390$ & 392 & $4-25$ & $139-836$ & $<0.03$ & $0.18^{\mathrm{a}}$ & $<0.09$ & $<0.02$ & $<0.01$ & $67-169$ & 21.2 & 1.06 & 1.26 \\
\hline TBBPA & $33-42.6$ & 45.2 & $493-517$ & 100 & NM & $<0.36^{\mathrm{a}}$ & $42 i$ & NM & NM & $8.2-18.9$ & $52^{\mathrm{a}}$ & 0.19 & $1.37^{\mathrm{a}}$ \\
\hline *PBCD & NM & 7.07 & $13-29$ & $42-351$ & $<0.03$ & $<0.09^{\mathrm{a}}$ & NM & $<0.03$ & NM & $2.7-9.0$ & 0.82 & $<0.13$ & NM \\
\hline
\end{tabular}

${ }^{a}$ Indicative value, due to analyte suppression on instrument; Range values quoted where repeatability is varied due to sample heterogeneity. 
Table 18. Polychlorinated napthalene (PCN) concentrations in waste samples (DS basis).

\begin{tabular}{|c|c|c|c|c|c|c|c|c|c|c|c|c|c|}
\hline & \multicolumn{2}{|c|}{ Biosolids } & \multicolumn{2}{|c|}{ CLO } & \multicolumn{2}{|c|}{ MBMA } & \multicolumn{2}{|c|}{ PLA } & \multirow[t]{2}{*}{ PSA } & \multicolumn{4}{|c|}{ RWW } \\
\hline & 1 & 2 & 1 & 2 & 1 & 2 & 1 & 2 & & 1 & 2 & 3 & 4 \\
\hline \multicolumn{14}{|c|}{$\mathrm{ng} \mathrm{kg}^{-1} \mathrm{DS}$} \\
\hline PCN 52 & 209 & 121 & 379 & $124^{\mathrm{a}}$ & 21.1 & 5.45 & $<1.84$ & 37.6 & $<8.22$ & $149^{\mathrm{a}}$ & $104^{\mathrm{a}}$ & 26.0 & 10.8 \\
\hline PCN 53 & 353 & 195 & 737 & $367^{\mathrm{a}}$ & 12.2 & $<1.80$ & $<1.78$ & 3.70 & $<7.98$ & $532^{a}$ & $348^{\mathrm{a}}$ & 60.0 & 46.6 \\
\hline PCN 66/67 & 14.6 & 20.4 & 30.5 & 9.95 & $<1.40$ & 2.94 & $<0.60$ & 8.92 & $<2.69$ & 12.6 & 6.99 & 1.18 & 0.87 \\
\hline PCN 68 & 31.0 & 31.0 & 107 & 30.6 & $<1.42$ & 1.87 & $<0.60$ & 5.64 & $<2.71$ & 76.5 & 25.6 & 5.09 & 4.11 \\
\hline PCN 69 & 42.7 & 38.9 & 223 & 47.4 & $<1.80$ & $<0.78$ & $<0.77$ & 1.55 & $<3.45$ & 130. & 38.5 & 8.17 & 6.74 \\
\hline PCN 71/72 & 66.1 & 52.0 & 370 & 62.6 & $<2.08$ & $<0.90$ & $<0.89$ & $<0.90$ & $<3.99$ & 203 & 55.1 & 15.3 & 14.2 \\
\hline PCN 73 & 12.8 & 39.4 & 40.1 & 18.8 & $<2.03$ & 43.9 & $<0.87$ & 1.69 & $<3.89$ & 28.5 & 10.7 & $<1.27$ & $<1.05$ \\
\hline PCN 74 & 12.1 & 19.1 & 85.7 & 15.2 & $<1.49$ & 20.7 & $<0.64$ & $<0.64$ & $<2.86$ & 67.6 & 13.9 & 2.27 & 2.99 \\
\hline PCN 75 & 1.42 & 25.0 & 4.01 & 5.64 & $<1.87$ & 29.6 & 0.80 & $<0.81$ & $<3.60$ & 11.0 & 4.69 & $<1.18$ & $<0.97$ \\
\hline Sum PCN, lower & 743 & 541 & 1980 & 680 & 33.3 & 104 & $<0.56$ & 59.1 & $<2.70$ & 1210 & 604 & 118 & 86.3 \\
\hline Sum PCN, upper & 743 & 541 & 1980 & 680 & 45.4 & 108 & 8.80 & 61.5 & 39.4 & 1210 & 604 & 121 & 88.3 \\
\hline
\end{tabular}

${ }^{a}$ Indicative value due to analyte suppression on instrument. CLO, compost-like-output; MBMA, meat and bone meal ash; PLA, poultry litter ash; PSA, paper sludge ash; RWW, recycled waste wood.

Table 19. Concentration ranges of Perfluroalkyl Substances (PFASs) in waste samples (DS basis).

\begin{tabular}{cccccccccc}
\hline & Biosolids & \multicolumn{3}{c}{ CLO } & \multicolumn{5}{c}{ RWW } \\
& $\mathbf{1}$ & $\mathbf{2}$ & $\mathbf{1}$ & $\mathbf{2}$ & $\mathbf{1}$ & $\mathbf{2}$ & $\mathbf{3}$ & $\mathbf{4}$ \\
\hline & \multicolumn{1}{c}{} & \multicolumn{1}{c}{$\boldsymbol{\mu g ~ \mathbf { ~ g } ^ { - 1 }} \mathbf{D S}$} \\
\hline Perfluorooctanoic acid (PFOA) [335-67-1] & $>10$ & $1-10$ & $>10$ & $1-10$ & $>10$ & $1-10$ & $1-10$ & $1-10$ \\
Perfluorooctane sulfonate (PFOS) [1763-23-1] & $>10$ & $>10$ & $1-10$ & $1-10$ & $1-10$ & $<1$ & $<1$ & $<1$ \\
Perfluorononanoic acid (PFNA) [375-95-1] & $>10$ & $1-10$ & $1-10$ & $1-10$ & $1-10$ & $<1$ & $<1$ & $1-10$ \\
Perfluorodecanoic acid (PFDA) [335-76-2] & $>10$ & $>10$ & $1-10$ & $1-10$ & $1-10$ & $<1$ & $<1$ & $<1$ \\
Perfluoroundecanoic acid (PFUnDA) [2058-94-8] & $1-10$ & $>10$ & $<1$ & $<1$ & $1-10$ & $<1$ & $1-10$ & $<1$ \\
Perfluorododecanoic acid (PFDoDA) [307-55-1] & $1-10$ & $1-10$ & $1-10$ & $<1$ & $1-10$ & $<1$ & $<1$ & $<1$ \\
\hline
\end{tabular}


Table 19. Cont.

\begin{tabular}{cccccccccc}
\hline & Biosolids & \multicolumn{3}{c}{ CLO } & \multicolumn{3}{c}{ RWW } \\
& $\mathbf{1}$ & $\mathbf{2}$ & $\mathbf{1}$ & $\mathbf{2}$ & $\mathbf{1}$ & $\mathbf{2}$ & $\mathbf{3}$ & $\mathbf{4}$ \\
\hline & \multicolumn{1}{c}{$\mathbf{M g ~ k g}^{-\mathbf{1}} \mathbf{D S}$} \\
\hline Perfluorobutane sulfonate (PFBS) [375-73-5] & $<1$ & $1-10$ & $1-10$ & $1-10$ & $<1$ & $<1$ & $<1$ & $<1$ \\
Pefluorohexanesulfonic acid (PFHxS) [355-46-4] & $<1$ & $1-10$ & $<1$ & $<1$ & $<1$ & $<1$ & $<1$ & $\mathrm{a}$ \\
Perfluorooctanesulfonamide (FOSA) [754-91-6] & $<10$ & $<1$ & $<1$ & $<1$ & $1-10$ & $<1$ & $<1$ & $<1$ \\
\hline
\end{tabular}

CLO, compost-like-output; RWW, recycled waste wood. PFCs were also measured in ash materials, and concentrations were $<1 \mu \mathrm{g} \mathrm{kg}{ }^{-1} \mathrm{DS}$ for all of the compounds;

${ }^{a}$ Data not quantifiable.

Table 20. Summary of key findings of Gas chromatography-time of flight-mass spectrometry (GC-ToF-MS) screen in comparison to concentrations of various organic contaminants in biosolids reported in the scientific literature.

\begin{tabular}{|c|c|c|c|c|}
\hline Contaminant & Biosolids & CLOs & Ash \& RWW & Literature Values (Biosolids) \\
\hline Di(2-ethylhexyl)phthalate (DEHP) & $15 \mathrm{mg} \mathrm{kg}^{-1} \mathrm{DS}$ & $5.6-11 \mathrm{mg} \mathrm{kg}^{-1} \mathrm{DS}$ & & $\begin{array}{l}58 \mathrm{mg} \mathrm{kg}^{-1} \mathrm{DS}^{\mathrm{a}} \\
11 \mathrm{mg} \mathrm{k}^{-1} \mathrm{DS}^{\mathrm{b}}\end{array}$ \\
\hline \multicolumn{5}{|l|}{ Chlorinated paraffins (CPs) } \\
\hline Medium chain & Biosolids2 (9 $\left.\mathrm{mg} \mathrm{kg}^{-1} \mathrm{DS}\right)$ & CLO1 (3 mg kg$\left.{ }^{-1} \mathrm{DS}\right)$ & & $910 \mathrm{mg} \mathrm{kg}^{-1} \mathrm{DS}^{\mathrm{a}}$ \\
\hline Short chain & Not detected & Not detected & & \\
\hline \multicolumn{5}{|l|}{ Chlorobenzenes (CBs) } \\
\hline $\mathrm{HCB}$ & $0.5 \mu \mathrm{g} \mathrm{kg}^{-1} \mathrm{DS}$ & $0.1 \mu \mathrm{g} \mathrm{kg}^{-1}$ & & \\
\hline $\mathrm{PeCB}$ & $0.5 \mu \mathrm{g} \mathrm{kg}^{-1} \mathrm{DS}$ & & & \\
\hline \multicolumn{5}{|l|}{ Polycyclic musks (PCM) } \\
\hline Galaxolide & Detected(not quantified) & $299-455 \mu \mathrm{g} \mathrm{kg}^{-1} \mathrm{DS}$ & & $141 \mu \mathrm{g} \mathrm{kg}^{-1} \mathrm{DS}^{\mathrm{a}}$ \\
\hline Tonalide & $850-900 \mu \mathrm{g} \mathrm{kg}^{-1} \mathrm{DS}$ & $39-52 \mu \mathrm{g} \mathrm{kg}^{-1} \mathrm{DS}$ & & $365 \mu \mathrm{g} \mathrm{kg}^{-1} \mathrm{DS}^{\mathrm{a}}$ \\
\hline \multicolumn{5}{|l|}{ Organophosphate flame retardants (OP FRs) } \\
\hline Tris(2-chloroisopropyl)phosphate (TCCP) & Biosolids1 & CLO1\&2 & PLA2; MBMA1; RWW1,2,4 & \\
\hline Tris(2-chloroethyl)phosphate (TCEP) & Biosolids1 & & PLA2 & \\
\hline
\end{tabular}

${ }^{\mathrm{a}}[53] ;{ }^{\mathrm{b}}[45]$ 
The $\mathrm{CBs}$, hexachlorobenzene $(\mathrm{HCB})$ and pentachlorobenzene $(\mathrm{PeCB})$ were detected at very low values of approximately $0.5 \mu \mathrm{g} \mathrm{kg}^{-1} \mathrm{DS}$ in the biosolids, and only HCB was found in the CLOs.

The PCM, tonalide was detected in the biosolids at concentrations of approximately $850-900 \mu \mathrm{g} \mathrm{kg}^{-1} \mathrm{DS}$ and in the CLOs at concentrations of $39-52 \mu \mathrm{g} \mathrm{kg}^{-1}$ DS. Galaxolide was detected in the CLOs at concentrations of 299-455 $\mathrm{g} \mathrm{kg} \mathrm{k}^{-1} \mathrm{DS}$, and was also detected in the biosolids, although quantification was not possible. Clarke and Smith [53] reported mean concentrations of galaxolide and tonalide in biosolids of 141 and $365 \mu \mathrm{g} \mathrm{kg}^{-1} \mathrm{DS}$, respectively.

Further work is required to quantify the phthalates, CPs, CBs and PCMs in the wastes in which they were detected by targeted analytical techniques.

The GC-ToF-MS screen also indicated the presence of several other organic contaminants of potential interest in the waste samples. The brominated flame-retardant, BTBPE, was detected in small amounts in both CLO samples. The wood preservative, pentachlorophenol (PCP), was detected in two of the recycled waste wood samples (RWW1 and 2), and a degradation product of PCP, pentachloroanisole, was detected in CLO2 and RWW2. Additionally, the organophosphate flame-retardant, tris(2-chloroisopropyl) phosphate (TCCP), was detected in 8 of the samples (Biosolids1, CLO1, CLO2, PLA2, MBMA1, RWW1, RWW2, RWW4) and tris(2-chloroethyl)phosphate (TCEP) was found in PLA2 and Biosoids1. These compounds and their metabolites are of interest due to their toxicity, their translocation from soil to crops [55] and their potential bioconcentration through the food chain [56,57]. Therefore these chemicals will also be investigated further in the waste materials and the transfer investigations to crops and milk.

\section{Conclusions}

The consignments of waste materials obtained for this investigation generally contained smaller concentrations of organic contaminants relative to reported literature values from earlier survey studies or environmental standards. Notably, the concentrations of PAHs, PCDDs/Fs and PCBs present in biosolids, CLOs and ash were significantly below proposed and implemented limit values for these compounds across Europe for biosolids, composts and recycled ash materials. For example, the TEQ of PCDD/Fs was approximately 10 times smaller than a previous EC proposal [26] for biosolids applied to agricultural land of $100 \mathrm{ng}$ TEQ $\mathrm{kg}^{-1}$ DS. The concentrations of PAHs in biosolids samples were also approximately 10 times smaller than the proposed limit of $6 \mathrm{mg} \mathrm{kg}^{-1} \mathrm{DS}$ [26], and the concentrations of PCBs were approximately 10-50 times below the proposed limit of $0.8 \mathrm{mg}^{-1} \mathrm{~kg}$ DS [26]. Additionally, the TEQ of PCDD/Fs present in PLA samples fell below the limit for the average of 10 samples of $10 \mathrm{ng}$ TEQ $\mathrm{kg}^{-1}$ in the UK Quality Protocol for the production and use of PLA [11]. This suggests that environmental emission controls have been effective at achieving significant reductions in the primary sources and release of these principal POPs to the environment [5]. Nevertheless, quantitative assessments of the potential risks to human health from PCDD/Fs, PCBs and PAHs in the environment may need up-dating and rationalizing to account for recent developments and improved understanding of their potential toxicology.

PBDD/Fs were present in larger amounts in the biosolids and CLOs compared to PCDD/Fs, and made a greater contribution to the overall TEQ. By contrast, individual congeners of mixed halogenated $\mathrm{PXDD} /$ Fs that could be analysed were present only in small concentrations. However, only a small 
number of the possible PXDD/F congeners could be quantified, hence the potential contribution of $\mathrm{PXDD} / \mathrm{Fs}$ to the overall TEQ is uncertain. These are some of the first data reporting the concentrations of brominated and mixed-halogenated dioxins, furans and biphenyls in different waste types for agricultural use, and they emphasise that they are potentially of greater contemporary significance for human health compared to emissions of their chlorinated counterparts, which have been controlled to a great extent.

PBDE flame retardants were detected in the biosolids, CLOs and RWWs in small concentrations, but, as they are destroyed in well managed combustion processes, as may be expected, were not found in the ash materials. The materials were also screened for a wide range of compounds using a GC-ToF-MS approach. Further work is required to quantify additional compounds including PFCs, phthalates, CPs, CBs, PCMs, the brominated flame-retardant BTBPE, the wood preservative PCP, and organophosphate flame-retardants in the waste types where these were detected in the non-target analysis.

Single, representative samples of each batch of waste material were analysed to determine the concentrations of organic contaminants in the wastes for the programme of experimental research to quantify transfers to crops and milk. However, significant variation in the concentrations of various contaminants in the different waste streams is likely, and further work should focus on investigating the variability of key compounds of interest.

The research programme will provide detailed information on the potential transfer to the foodchain of organic contaminants in waste materials recycled in agriculture. This new and quantitative data will aim to improve the robustness of risk assessments and confidence in the use of these materials in agriculture, and establish guidelines where necessary to protect the food chain.

\section{Acknowledgments}

The Authors gratefully acknowledge the Food Standards Agency for funding the research. The opinions and conclusions expressed in this article are solely the views of the authors and do not necessarily reflect those of the Food Standards Agency.

We would like to thank Sophia Acker' and Radu Rautiu, Imperial College London Consultants for project management, and Malcolm Drifford, Fera, for his contribution to the text on the GC-ToF-MS screen methodology.

\section{Author Contributions}

Stephen R. Smith conceived, designed and directed the experimental work. Hannah Rigby conducted the technical aspects of the project with assistance from all co-authors. Martin Rose, Alwyn Fernandes and Rupert G. Petch conducted the chemical analysis of organic contaminants. All authors analysed the data. Hannah Rigby wrote the paper. All authors revised the article.

\section{Conflicts of Interest}

The authors declare no conflict of interest. 


\section{References}

1. EC: European Commission. Roadmap to a Resource Efficient Europe; EC: Brussels, Belgium, 2011.

2. Smith, S.R. Agricultural Recycling of Sewage Sludge and the Environment; CABI, Wallingford, UK, 1996.

3. Carbonell, G.; de Imperial, R.M.; Torrijos, M.; Delgado, M.; Rodriguez, J.A. Effects of municipal solid waste compost and mineral fertilizer amendments on soil properties and heavy metals distribution in maize plants (Zea mays L.). Chemosphere 2011, 85, 1614-1623.

4. Amlinger, F.; Pollak, M.; Favoino, E. Heavy Metals and Organic Compounds from Wastes Used as Organic Fertilisers; Final Report to DG Environment: Brussels, Belgium, 2004.

5. Smith, S.R.; Riddell-Black, D. Sources and Impacts of Past, Current and Future Contamination of Soil. Appendix 2: Organic contaminants; Final Report to Defra: London, UK, 2015.

6. Rigby, H.; Acker, S.; Dowding, A.; Fernandes, A.; Humphries, D.; Petch, R.G.; Rautiu, R.; Reynolds, C.K.; Rose, M.; Smith, S.R. The Physico-chemical Properties and Concentrations of Organic Contaminants in Waste Materials Recycled in Agriculture. In Proceedings of Tinos2015 3rd International Conference on Sustainable Solid Waste Management, Tinos Island, Greece, 2-4 July 2015; ISWM-TINOS: Tinos Island, Greece, 2015.

7. Smith, S.R. Organic contaminants in sewage sludge (biosolids) and their significance for agricultural recycling. Philos. T. Royal Soc. 2009, 367, 3871-3872.

8. van Asselt, E.D.; Kowalczyk, J.; van Eijkeren, J.C.H.; Zeilmaker, M.J.; Ehlers, S.; Fürst, P.; Lahrssen-Wiederholt, M.; van der Fels-Klerx, H.J. Transfer of perfluorooctane sulfonic acid (PFOS) from contaminated feed to dairy milk. Food Chem. 2013, 141, 1489-1495.

9. Blaine, A. C.; Rich, C.D.; Hundal, L.S.; Lau, C.; Mills, M.A.; Harris, K.M.; Higgins, C.P. Uptake of Perfluoroalkyl Acids into edible crops via land applied biosolids: Field and greenhouse studies. Environ. Sci. Technol. 2013, 47, 14062-14069.

10. Wen, B.; Li, L.; Zhang, H.; Ma., Y.; Shan, X.-Q.; Zhang, S. Field study on the uptake and translocation of perfluoroalkyl acids (PFAAs) by wheat (Triticum aestivum L.) grown in biosolids-amended soils. Environ. Pollut. 2014, 184, 547-554.

11. Fernandes, A.; White, S.; D’Silva, K.; Rose, M. Simultaneous determination of PCDDs, PCDFs, PCBs and PBDEs in food. Talanta 2004, 63, 1147-1155.

12. Fernandes, A.; Dicks, P.; Mortimer, D.; Gem, M.; Smith, F.; Driffield, M.; White, S.; Rose, M. Brominated and chlorinated dioxins, PCBs and brominated flame retardants in Scottish shellfish: Methodology, occurance and human dietary exposure. Mol. Nutr. Food Res. 2008, 52, 238-249.

13. Wrap and EA, Waste and Resources Action Programme and Environment Agency. Quality Protocol for Poultry Litter Ash. End of Waste Criteria for the Production and Use of Treated Ash from the Incineration of Poultry Litter, Feathers and Straw; Wrap: Banbury, UK, 2012.

14. WRAP, Waste and Resources Action Programme. Specification for the Requirements and Test Methods for Processing Waste Wood; BSI: London, UK, 2011.

15. EU: European Union Commission Regulation. Laying down methods of sampling and analysis for the official control of levels of dioxins, dioxin- like PCBs and non-dioxin-like PCBs in certain foodstuffs and repealing Regulation (EC) No 1883/2006. Off. J. EU 2012, L81, 1-22. 
16. Fernandes, A.R.; Rose, M.; Mortimer, D.; Carr, M.; Panton, S.; Smith, F. Mixed brominated/chlorinated dibenzo- $p$-dioxins, dibenzofurans and biphenyls: Simultaneous congener-selective determination in food. J. Chromatogr. A 2011, 1218, 9279-9287.

17. Rose, M.; White, S.; Macarthur, R.; Petch, R.G.; Holland, J.; Damant, A.P. Single-laboratory validation of a GC/MS method for the determination of 27 polycyclic aromatic hydrocarbons (PAHs) in oils and fats. Food Addit. Contam. 2007, 6, 635-651.

18. Fernandes, A.; Mortimer, D.; Gem, M.; Smith, F.; Rose, M.; Penton, S.; Carr, M. Polychlorinated Naphthalenes (PCNs): Congener Specific Analysis, Occurrence in Food, and Dietary Exposure in the UK. Environ. Sci. Technol. 2010, 44, 3533-3538.

19. Lloyd, A.S; Bailey, V.A.; Hird, S.J.; Routledge, A.; Clarke, D.B. Mass spectral studies towards more reliable measurement of perfluorooctanesulfonic acid and other perfluorinated chemicals (PFCs) in food matrices using liquid chromatography/tandem mass spectrometry. Rapid Commun. Mass Spec. 2009, 23, 2923-2938.

20. Rigby, H.; Perez-Viana, F.; Cass, J.; Rogers, M.; Smith, S.R. The influence of soil and biosolids type, and microbial immobilisation on nitrogen availability in biosolids-amended agricultural soils_-Implications for fertiliser recommendations. Soil Use Manage. 2009, 25, 395-408.

21. Rigby, H.; Smith, S.R. Nitrogen availability and indirect measurements of greenhouse gas emissions from aerobic and anaerobic biowaste digestates applied to agricultural soils. Waste Manage. 2013, 25, 395-408.

22. SI: Statutory Instrument. The Sludge (Use in Agriculture) Regulations; HMSO: London, UK, 1989.

23. Gendebien, A.; Davis, B.; Hobson, J.; Palfrey, R.; Pitchers, R.; Rumsby, P.; Carlton-Smith, C.; Middleton, J. Environmental, Economic and Social Impacts of the Use of Sewage Sludge on Land, Assessment of Existing Knowledge; Milieu Ltd.: Brussels, Belgium, 2008.

24. Smith, S.R. A critical review of the bioavailability and impacts of heavy metals in municipal solid waste composts compared to sewage sludge. Environ. Int. 2009b, 35, 142-156.

25. Defra: Department of Environment, Food and Rural Affairs. Fertilizer Manual (RB209), 8th ed.; The Stationery Office: Norwich, UK, 2010.

26. Davou, E. Environmental Impacts of Recycled Wood; Master's Thesis, Department of Civil and Environmental Engineering, Imperial College London: London, UK, 2014.

27. UKSHS: UK Soil and Herbage Pollutant Survey. Introduction and Summary; Environment Agency: Oxon, UK, 2007.

28. UKSHS: UK Soil and Herbage Pollutant Survey. Environmental Concentrations of Polychlorinated Dibenzo-p-dioxins and Polychlorinated Dibenzofurans in UK Soil and Herbage; Environment Agency: Oxon, UK, 2007.

29. UKSHS: UK Soil and Herbage Pollutant Survey. Environmental Concentrations of Polychlorinated Biphenyls (PCBs) in UK Soil and Herbage; Environment Agency: Oxon, UK, 2007.

30. UKSHS: UK Soil and Herbage Pollutant Survey. Environmental Concentrations of Polycyclic Aromatic Hydrocarbons in UK Soil and Herbage; Environment Agency: Oxon, UK, 2007.

31. EC: European Commission. Proposal for a Directive of the European Parliament and of the Council on Spreading of Sludge on Land; European Commission: Brussels, Belgium, 2003.

32. US EPA: US Environmental Protection Agency. Technical Support Document for Land Application of Sewage Sludge; Eastern Research Group: Lexington, MA, USA, 1992. 
33. US EPA: US Environmental Protection Agency. Technical Support Document for Land Application of Sewage Sludge, Appendices; Eastern Research Group: Lexington, MA, USA, 1992.

34. WEAO: Water Environment Association of Ontario. Fate and Significance of Selected Contaminants in Sewage Biosolids Applied to Land through Literature Review and Consultation with Stakeholder Groups; WEAO: Aurora, Ontario, Canada, 2001.

35. Blackmore, K.; Davis, L.; Davis, M.; Davis, R.; Gendebien, A. Accommodating the Implications of the Revised EU Sludge Directive; UKWIR: London, UK, 2006.

36. VKM: Norwegian Scientific Committee for Food Safety. Risk Assessment of Contaminants in Sewage Sludge Applied on Norwegian Soils; VKM: Oslo, Norway, 2009.

37. Saveyn, H.; Eder, P. End-of-Waste Criteria for Biodegradable Waste Subjected to Biological Treatment (Compost \& Digestate): Technical Proposals; Publications office of the European Union: Luxembourg, Luxembourg, 2014.

38. Office of the Federal Registration. Appendix A: priority pollutants; Washington, DC, USA, 1982.

39. Gong, Y. Agricultural Environmental Impacts of Recycled Biomass Ashes. Master's Thesis, Department of Civil and Environmental Engineering, Imperial College London: London, UK, 2014.

40. Elskens, M.; Pussemier, L.; Dumortier, P.; Van Langenhove, K.; Scholl, G.; Goeyens, L.; Focant, J.F. Dioxin levels in fertilizers from Belgium: Determination and evaluation of the potential impact on soil contamination. Sci. Total Environ. 2013, 454, 366-372.

41. Dumortier, P.; Elskens, M.; Goeyens, L.; Vandermeiren, K.; Focant, J.F.; Pussemier, L. Potential impact of fertilization practices on human dietary intake of dioxins in Belgium. Sci. Total Environ. 2012, 423, 47-54.

42. Venkatesan, A.K.; Halden, R.U. Contribution of polybrominated dibenzo-p-dioxins and dibenzofurans (PBDD/Fs) to the toxic equivalency of dioxin-like compounds in archived biosolids from the US EPA's 2001 National Sewage Sludge Survey. Environ. Sci. Technol. 2014, 48, 10843-10849.

43. Fernandes, A.R.; Mortimer, D.; Wall, R.J.; Bell, D.R.; Rose, M.; Carr, M.; Panton, S.; Smith, F. Mixed halogenated dioxins/furans (PXDD/Fs) and biphenyls (PXBs) in food: Occurrence and toxic equivalent exposure using specific relative potencies. Environ. Int. 2014, 73, 104-110.

44. Larsen, J. C. Scientific opinion of the panel on contaminants in the food chain on a request from the European Commission on polycyclic aromatic hydrocarbons in food. EFSA J. 2008, 724, $1-114$.

45. Jones, V.; Gardner, M.; Ellor, B. Concentrations of trace substances in sewage sludge from 28 wastewater treatment works in the UK. Chemosphere 2014, 111, 478-484.

46. Trably, E.; Patureau, D.; Delgenes, J.P. Enhancement of polycyclic aromatic hydrocarbons removal during anaerobic treatment of urban sludge. Water Sci. Tecnol. 2003, 48, 53-60.

47. Rogers, H.R. Sources, behaviour and fate of organic contaminants during sewage treatment and in sewage sludges. Sci. Total Environ. 1996, 185, 3-26.

48. Knoth, W.; Mann, W.; Meyer, R.; Nebhuth, J. Polybrominated diphenyl ether in sewage sludge in Germany. Chemosphere 2007, 67, 1831-1837.

49. North, K.D. Tracking polybrominated diphenyl ether releases in a wastewater treatment plant effluent, Palo Alto, California. Environ. Sci. Technol. 2004, 38, 4484-4488. 
50. EU: European Union. Regulation relating to restrictions on the marketing and use of certain dangerous substances and preparations (pentabromodiphenyl ether, octabromodiphenyl ether). Off. J. EU 2003, L42, 45-46.

51. EC: European Commission. Regulation on persistent organic pollutants and amending. Off. J. EU 2004, L158, 7-49.

52. Mark, F.E.; Vehlow, J.; Dresch, H.; Dima, B.; Gruttner, W.; Horn, J. Destruction of the flame retardant hexabromocyclododecane in a full-scale municipal solid waste incinerator. Waste Manage. Res. 2015, 33, 165-174.

53. Clarke, B.O.; Smith, S.R. Review of 'emerging' organic contaminants in biosolids and assessment of international research priorities for the agricultural use of biosolids. Environ. Int. 2011, 37, 226-247.

54. Noma, Y.; Yamamoto, T.; Giraud, R.; Sakai, S. Behavior of PCNs, PCDDs, PCDFs, and dioxin-like PCBs in the thermal destruction of wastes containing PCNs. Chemosphere 2006, 62, 1183-1195.

55. Eggen, T.; Heimstad, E.S.; Stuanes, A.O.; Norli, H.R. Uptake and translocation of organophosphates and other emerging contaminants in food and forage crops. Environ. Sci. Pollut. Res. 2013, 20, 4520-4031.

56. Sundkvist, A.M.; Olofsson, U.; Haglund, P. Organophosphorus flame retardants and plasticizers in marine and fresh water biota and in human milk. J. Environ. Monit. 2010, 12, 943-951.

57. Eulaers, I.; Jaspers, V.L.B.; Halley, D.J.; Lepoint, G.; Nygård, T.; Pinxten, R.; Covaci, A.; Eens, M. Brominated and phosphorus flame retardants in White-tailed Eagle Haliaeetus albicilla nestlings: Bioaccumulation and associations with dietary proxies $(\delta 13 \mathrm{C}, \delta 15 \mathrm{~N}$ and $\delta 34 \mathrm{~S})$. Sci. Total Environ. 2014, 478, 48-57.

(C) 2015 by the authors; licensee MDPI, Basel, Switzerland. This article is an open access article distributed under the terms and conditions of the Creative Commons Attribution license (http://creativecommons.org/licenses/by/4.0/). 